\title{
Pathophysiology of headaches with a prominent vascular component
}

\author{
Juan A Pareja MD, Linda R White PhD, Ottar Sjaastad MD PhD
}

\author{
JA Pareja, LR White, O Sjaastad. \\ Pathophysiology of headaches with a prominent vascular \\ component. \\ Pain Res Manage 1996;1(2):93-108.
}

Vascular changes, whether preliminary or secondary, seem to accompany most headaches. The literature concerning pathophysiological mechanisms in headaches where vascular phenomena are a major, integral part, ie, migraine and cluster headache syndrome, is reviewed and the most common forms of headache associated with cerebrovascular disease are discussed. Emphasis is placed on the vascular phenomena and on the abundant hypotheses and theories regarding headache mechanisms. This review also presents altemative explanatory models, and compares the available anatomical, physiological and biochemical results.

Key Words: Chronic paroxysmal hemicrania, Cluster headache, Headache, Migraine, Revien', Subarachnoid hemorrhage

\section{Physiopathologie des céphalées à composante vasculaire dominante}

RÉSUMÉ : Les changements vasculaires, qu'ils soient primaires ou secondaires, semblent accompagner la plupart des céphalées. La littérature concernant les mécanismes physiopathologiques des céphalées où les phénomènes vasculaires jouent un rổle entier et important, par exemple, dans les cas de migraine ou de céphalée en chapelet, est passée en revue, et les formes les plus communes de céphalées associées à une maladie cérébrovasculaire sont discutées. On insiste sur les phénomènes vasculaires et sur les nombreuses hypothèses et théories concernant les mécanismes des céphalées. La présente revue propose aussi un choix de modèles explicatifs at compare les données biochimiques, physiologiques et anatomiques disponibles.
$\mathrm{V}$ ascular changes, whether preliminary or secondary, seem to accompany most headaches. The impact of vascular changes in the pathogenesis of any special type of headache is important. Another key aspect is how specific the vascular changes are in each particular type of headache.

Migraine and cluster headache $(\mathrm{CH})$ have been classified as 'vascular' headaches (1), suggesting that prominent, vascular changes affecting intra- or extracranial vessels not only accompany the attack, but also are of primary importance in the pathogenesis of both types of headache. These vascular abnormalities may be specific for migraine and $\mathrm{CH}$, regarding both the distribution of the vascular changes and the nature of each type. However, because etiology and pathogenesis are largely un- known in these types of headaches, one must be cautious delineating both the origin and the significance of the vascular phenomena. It may be more appropriate to classify them as 'primary headaches' without introducing a prejudgement of possible vascular origin, despite the relative prominence of vascular features in both types of headaches. The International Headache Society (IHS) classification of headache (2) does not employ the term 'vascular headaches' for migraine and $\mathrm{CH}$.

Cerebral vessels are not known to show any evidence of a stationary, organic disorder in these headaches. Appropriate investigations should rule out such a possibility in solitary cases showing slightly deviating traits; as a minimum, computed tomography scan should used, as well as magnetic resonance imaging

Department of Neurology, University Hospital of Trondheim, Trondheim, Nonway; and Minnesota Regional Sleep Disorders Center, Hennepin County Medical Center, Minneapolis, Minnesota, USA

Correspondence and reprints: Dr LR White, Department of Neurology, University Hospital of Trondheim, N-7006 Trondheim, Norway. Telephone 477-399-8412, fax 477-399-7581

Received for publication September 8, 1995. Accepted February 27, 1996 


\section{TABLE 1}

\section{Causes of secondary headaches}

\section{Head trauma}

Vascular disorders

Nonvascular intracranial disorders

Substance use or withdrawal

Noncephalic infection

Metabolic disorders

Disorders of cranium, neck, eyes, ears, nose, sinuses, teeth, mouth or other facial or cranial structure

Cranial neuralgias, nerve trunk pain and deafferentation pain

Adapted from reference 2

(MRI) if available. This is especially important in $\mathrm{CH}$ where many patients with a symptomatic form have been described. Female sex, a blunted cluster pattern and a shift of maximal pain from the fronto-ocular to the more posterior areas are traits that should alert the clinician.

Furthermore, headache may be a symptom of various pathological disorders, which supplementary investigations can show to have a vascular component. The underlying disease may produce headache by a pathophysiological mechanism affecting the cranial vessels and pain-sensitive structures. Thus, such headaches are secondary or symptomatic (Table 1). Secondary vascular headaches are brought about by an identifiable disorder affecting cerebral vessels.

This report reviews the pathophysiology of migraine, $\mathrm{CH}$ and the more frequent headaches associated with cerebrovascular disease. The terms 'primary vascular headache' and 'secondary vascular headache' should be kept in mind as a useful clinical concept.

\section{MIGRAINE}

Migraine is characterized by episodes of head pain of moderate to severe intensity. Pain is typically pulsatile and unilateral (with alternation of sides). Attacks are accompanied by nausea, vomiting and phono- and photophobia.

Although migraine is a common disease, known for centuries, both its etiology and pathogenesis are still not well understood. Although the classification of migraine includes several subtypes, only migraine with and without aura ('classic' and 'common' migraine [1]) will be considered here. Despite clinical differences among different subtypes, the underlying pathogenesis may prove to be similar or even identical for many, if not all, forms of migraine. Common migraine may, nevertheless, turn out to be a heterogeneous group of headaches.

More than 50 years ago, Wolff (3) and Graham and Wolff (4) advanced a 'classic' theory concerning the pathophysiology of migraine. They proposed that a brief period of intracranial vasoconstriction was the cause of the initial, focal symptoms of the attack ('aura'). After that, an arterial dilation, to a large extent extracranially, would produce the headache. This theory has been modified, rejected and somewhat revived. Compared with this classic theory, a central or 'neuronal' hypothesis has also been advanced (see, for example, 5-7). According to this 'neuronal' hypothesis, a primary neuronal disturbance antedates the vascular phenomena of the attack and is responsible for the aura symptoms. The typical changes in cerebral bloodflow would accordingly be secondary to the neural involvement.

However, regardless of the first event, it seems that both vascular and neuronal dysfunction are crucial factors in the pathophysiology of migraine.

\section{Vascular phenomena}

Studies from the '70s and ' $80 \mathrm{~s}(8-11)$ demonstrated that regional cerebral bloodflow (rCBF) decreased in the supposedly affected hemisphere of the aura during a migraine attack. This local hypoperfusion usually started in the occipital region and subsequently seemed to spread anteriorly at a certain rate, but the extension of the oligemia had no relationship with any specific vascular territory. These findings, combined with the fact that the cerebral hypoperfusion did not seem to reach the ischemic range, were arguments that at least partly favoured the theory of neuronal dysfunction as the first event of the migraine attack. Primary neuronal involvement might lead to a reduced demand for oxygen, merely because of the state of the neurons. Neuronal dysfunction might produce the aura symptoms and, secondarily, the hypoperfusion.

The similarity of the progression of the oligemia to that of the neuronal cortical spreading depression (CSD) described by Leão (12) in animal experiments is particularly interesting. The latter phenomenon may be triggered by, for example, physical and chemical stimuli, and starts with a short-lasting 'electrical storm', in the wake of which is a neuronal 'silence'. The neuronal inactivation is transient and is followed by repolarization which fully restores function. The neuronal depolarization spreads at a rate of 2 to $3 \mathrm{~mm} / \mathrm{min}$. The rate of visual aura progression corresponds to the velocity of expansion of the process in the occipital cortex of around $3 \mathrm{~mm} / \mathrm{min}$ (13). Thus, there seem to be spatial and temporal similarities between CSD, and visual aura progression and spreading oligemia.

Furthermore, it was demonstrated that at pain onset rCBF was still decreased in the corresponding cerebral area. The fact that the oligemia is persistent argues, to some extent, against the concept of arterial dilation as a cause of the pain. However, the possibility still existed at that stage that vasodilation started intracranially but outside the brain, or even started extracranially.

Later, however, Skyhöj Olsen and Lassen (14) demonstrated that the hypoperfusion during the aura phase was more marked than previously conjectured, the oligemia appearing to reach the ischemia range. Results obtained with the technique they used (rCBF with intracarotid ${ }^{133} \mathrm{Xe}$ ) may have been influenced by the Compton scatter effect $(15,16)$, which overestimates rCBF. It is therefore possible that the cerebral hypoperfusion had been underestimated (17). There is also evidence suggesting that the regional hypoperfusion during the aura phase of migraine is not secondary to reduced cerebral metabolic activity (18).

In theory, therefore, the focal symptoms during the aura may be due to neuronal ischemia. The spreading oligemia may be interpreted as an artefact caused by the Compton scatter effect 
(17). The gradual decrease of the $\mathrm{rCBF}$ in a cerebral territory not changing in size can give the impression of spreading when the intracarotid ${ }^{133} \mathrm{Xe}$ technique is used. Fast oscillations in $\mathrm{rCBF}$ may produce a false impression of spreading, and variations in cerebral perfusion probably reflect vascular instability of the ischemic area (19).

The characteristic aura 'marche' may be due to the different sensitivity of various neuronal areas to the ischemia. The sensitivity to hypoxia may vary in different cerebral regions (20). In different individuals, there may even be variation in sensitivity over time.

Together those new findings somewhat revived the vascular theory of migraine and the old concept of arterial spasm leading to ischemia during the aura. However, CSD has never convincingly been demonstrated in the neocortex of humans in vivo. A process such as CSD, nevertheless, may provide a good explanation for the aura symptoms and especially for the characteristic marche,

The aura appears during focal oligemia (21), and the focal neurological symptoms seem to correlate with the side of the hypoperfusion in both adults and children (22). After headache onset, the rCBF gradually increases to the hyperperfusion range. Hyperemia may be a reaction to the previous oligemia and be produced by metabolic products (23), or it may be related to the repolarization phase of CSD or even the pathophysiological mechanisms of pain (24). In about $24 \mathrm{~h}$ the attack-induced rCBF abnormalities grossly disappear.

Both neurophysiological and neuroimaging studies have been employed to demonstrate persistent neuronal damage (25-31). There is evidence that some migraineurs may have brain lesions that are probably ischemic in nature. MRI studies have demonstrated an increase in small, hyperintense signals in T2 series in migraine sufferers. These small lesions may represent microinfarcts $(30,31)$, but whether they were related to migraine has not been demonstrated because they were also found in headachefree control individuals.

Magnetic resonance spectroscopy studies have shown that during attacks there is no change in intracellular $\mathrm{pH}$ (32), which argues against an ischemic origin of aura. Moreover, magnetic resonance spectroscopy studies are consistent with a neuronal (and, to some extent, extraneuronal) disorder in oxidative energy metabolism in migraine sufferers that has been attributed to a mitochondrial metabolic defect $(33,34)$. There is evidence for a systemic and brain magnesium deficiency (35), which may result in abnormal mitochondrial phosphorylation. Taking all these things into consideration, Welch et al (36) have proposed the theory that there is neuronal hyperexcitability in migraine due to abnormal mitochondrial metabolic function and magnesium deficiency. This can create a predisposition to CSD, either spontaneously or triggered by a migraine process. Magnetoencephalographic findings during migraine attacks have been claimed to indicate CSD (37), again supporting the neuronal theory.

There is some clinical evidence that migraine with and without aura are facets of the same disease (see, for example, 38). If so, the underlying mechanism would be the same, but the vascular process can be more intense in migraine with aura (20). In this connection, moderate rCBF changes would not be detected by the current techniques that require a decrease in $\mathrm{CCBF}$ of at least $20 \%$ with the inherent sensitivity of the procedure. Alternatively, migraine without aura could start in a different 'silent' area.

\section{Vasospasm and complicated migraine}

In most cases, cerebral hypoperfusion during migraine aura is brief and apparently well tolerated. On rare occasions, aura is long lasting (39-41); cerebral infarcts may follow $(42,43)$. This may be due to particularly intense and/or long lasting hypoperfusion.

A sustained vasospasm is a possible mechanism that can underlie complicated migraine. Other putative factors, including platelet hyperaggregability (44), antiphospholipid antibodies and lupus anticoagulant $(45,46)$, arterial dissection (47) and mitral valve prolapse (48), have also been reported as main or additional factors in production of the migrainous infarct $(42,43)$. Even a relationship between migraine and arteriopathy (arteritis, atherosclerosis, intimal hyperplasia) has been conjectured (49-51).

None of the disorders or factors mentioned above has been proven to be directly responsible for migrainous stroke (52-54), but it is possible that a combination of intense cerebral hypoperfusion and some of the disorders mentioned (eg, platelet hyperaggregation) is necessary.

In some patients a transcranial Doppler study (55) or an angiography were carried out during 'complicated' and 'noncomplicated' migraine attacks. Studies of this type have claimed to show a narrowing of one or more intracranial arteries during episodes of complicated migraine $(41,51,56,57)$. Furthermore, the observed segmentary narrowing seemed to be related to an arterial vasospasm because serial angiograms demonstrated the reversibility of the arterial stenosis. The possibility nevertheless exists that the decrease in arterial lumen is not due to vasospasm (56).

In migraine, vasospasm may be the cause of the cerebral hypoperfusion during the aura, and eventually a single, but long lasting and severe episode of vasospasm may cause or contribute to the ischemic complications of migraine. It is also possible that repetitive episodes of vasospasm of long duration may result in damage of the cerebral vessels, making them more susceptible to factors that may produce cerebral infarct in young people.

Sustained vasospasm is also associated with subarachnoid hemorrhage (SAH), but this will be dealt with more fully in a later section. It is now clear, however, that SAH and migraine have several neurobiological changes in common. Elevated plasma levels of endothelin-1, the strong vasoconstricting peptide produced by endothelial cells (58), are found in patients with SAH (59), ischemic cerebrovascular disease (60) and migraineurs (61), both during and outside attacks (62).

Additionally, experiments in vitro have shown that vasoconstriction induced by subarachnoid blood appears to activate the trigeminovascular system (63). Increased release of calcitonin gene-related peptide (CGRP) has been demonstrated following $\mathrm{SAH}(64,65)$, and brain vessels taken from patients who had died following SAH had barely detectable levels of CGRP compared with vessels from patients dying of other causes $(66,67)$. Such results suggest that the trigeminovascular system may be in- 
volved in the restoration of vascular tone through a reflex system. The trigeminovascular system has long been suspected to play a role in headache pathophysiology (68). Such a theory is supported by results showing increased levels of CGRP-like immunoreactivity in extracranial blood samples from migraine patients during attacks (69), and by the observation that peptide levels return to normal in patients who obtain relief from sumatriptan or dihydroergotamine (70).

May migraine-related vasospasm produce the same vascular lesions as SAH? Any sufficiently intense, long lasting or repetitive arterial spasm may lead to a vascular lesion (56). However, it seems unlikely that the migraine vasospasm may be of the nature and intensity of the spasm associated with SAH.

\section{Pain mechanisms}

The pain of the migraine attack can originate from activation of intracranial sensory nerves because a major fraction of the cranial vessels are subserved by sensory fibres from the trigeminal nerve (71). This trigeminovascular system furnishes fibres to the anterior, middle and posterior cerebral arteries, and to the meningeal arteries. These vessels are innervated by the ipsilateral trigeminal branches, but the anterior cerebral artery and the longitudinal sinus receive bilateral innervation. The basilar and vertebral arteries are innervated by the upper cervical segments.

Autonomic vasodilator innervation for vessel smooth muscle is also provided by parasympathetic fibres from the facial nerve, whereas vasoconstrictor fibres stem from sympathetic nerves. The parasympathetic part of the facial nerve originates in the superior salivary nuclei that project to the sphenopalatine and otic ganglia. Superficial petrosal nerves furnish the fibres that end in the arterial smooth muscle. Activation of these fibres causes relaxation, and the main vasoactive substances implicated are acetylcholine and vasoactive intestinal peptide (VIP). Autonomic vasoconstrictor pathways stem from the first thoracic spinal segments via the superior cervical ganglion. The important transmitters are noradrenaline and neuropeptide $Y(71)$.

Sensory stimuli travel via the trigeminovascular system to the Gasserian ganglion which, in turn, makes central synapsis with the trigeminal subnucleus caudalis, dorsolateral horn grey matter (at the level C3) and neurons of the dorsolateral white matter (level C2) (72). These cellular groups are part of the trigeminospinal nuclei. After synapsing, they cross the midline and project rostrally via ascending fibre systems (trigeminothalamic tract). Finally, from the thalamus, the sensory stimuli reach the cerebral cortex.

Trigeminovascular fibres are nonmyelinated, $C$ type fibres. They contain vesicles with sensory neuropeptides, including CGRP, substance $\mathrm{P}$ (SP) and neurokinin A. These peptides may be released locally in an antidromic way in response to excitation of the neurons via local axonic reflexes $(73,74)$.

Change in arterial width produces geometric alteration in the adventitia. This may be a factor that is necessary for triggering depolarization of the trigeminovascular sensory endings, although a combination of factors may be necessary for such triggering. Ischemic and/or other neuronal alterations, as with $\mathrm{CSD}$, can be contributory factors for the activation of the trigeminovascular system.
Cellular damage, for instance arising from ischemia, produces the release of excitatory amino acid neurotransmitters, notably glutamate and aspartate (75), which stimulate neurons with subsequent disturbance of calcium homeostasis, resulting in an excess influx of calcium ions to the cell (76).

Concomitantly, the reduced availability of energy sources results in a reduction of $\mathrm{ATP}$-driven metabolism, including the $\mathrm{Ca}^{2+}$-ATPase pump and $\mathrm{Na}^{+}-\mathrm{Ca}^{2+}$ antiporter which are primarily responsible for removing excess calcium from the cell. An uncontrolled high intracellular level of calcium carries a danger of overstimulation of calcium-mediated processes, including activation of proteases and lipases, and the generation of free radicals. This can lead to further damage of cellular membranes (76). In addition, excitatory amino acids may activate agonistoperated ion channels, leading to osmolytic damage (77).

Primary stimulating agents such as hormones and neurotransmitters exert their effects by binding to specific receptors, their chemical information being mediated to key effector enzymes in the membrane, such as adenylate cyclase (78), phospholipase $\mathrm{A}_{2}$ (79), or phospholipase $C(80)$, and then through second messengers. Activation of phospholipase $\mathrm{C}$ may also lead to an increase in intracellular calcium $(81,82)$. Other intracellular events initiated may include the release of other transmitter substances, and there is clearly an intricate system of activation and inhibition of these systems by each other (83). The relationship between putative excitotoxic mechanisms and trigeminovascular activation has still to be determined (84).

Receptor-mediated activation of phospholipase $A_{2}$ will result in hydrolysis of membrane phospholipids and release of arachidonic acid (81), which is the main precursor for a number of other active substances such as prostaglandins, thromboxanes and leukotrienes (85). Arachidonic acid has been found in high concentrations in brain during ischemia (86) and may be in volved as a direct messenger in pathological processes, releasing sequestered calcium to the cytoplasm (87).

Tissue damage, subendothelial collagen or both activate the local and intravascular production of algogenic/nociceptive substances such as bradykinin (from alpha 2 -macroglobulin), histamine (from mast cells), serotonin (from blood platelets) and metabolites of arachidonic acid. A prostaglandin such as $\mathrm{PGE}_{1}$, which has been shown to create migraine-like attacks in healthy volunteers (88), may sensitize sensory nerve endings, thereby decreasing the pain threshold and enhancing the algogenic action of other factors (89).

Irrespective of the route of trigeminovascular activation, the excitation of Gasserian neurons will produce antidromic release of vasodilatory peptides such as SP, neurokinin A and CGRP. SP in particular is believed to contribute to both painful dilation of cranial vessels and plasma extravasation, typical of neurogenic inflammation (90). SP may also trigger the release of other factors, such as histamine (91) and serotonin. SP has now been shown to be released from endothelial cells (92), so it is not clear whether the two sources play different roles in pathophysiological situations.

Neurogenic inflammation mostly affects the vessels of the cerebral cortex and the dural venous system (Figure 1). As a result, the functional integrity of the blood-brain barrier (BBB) 


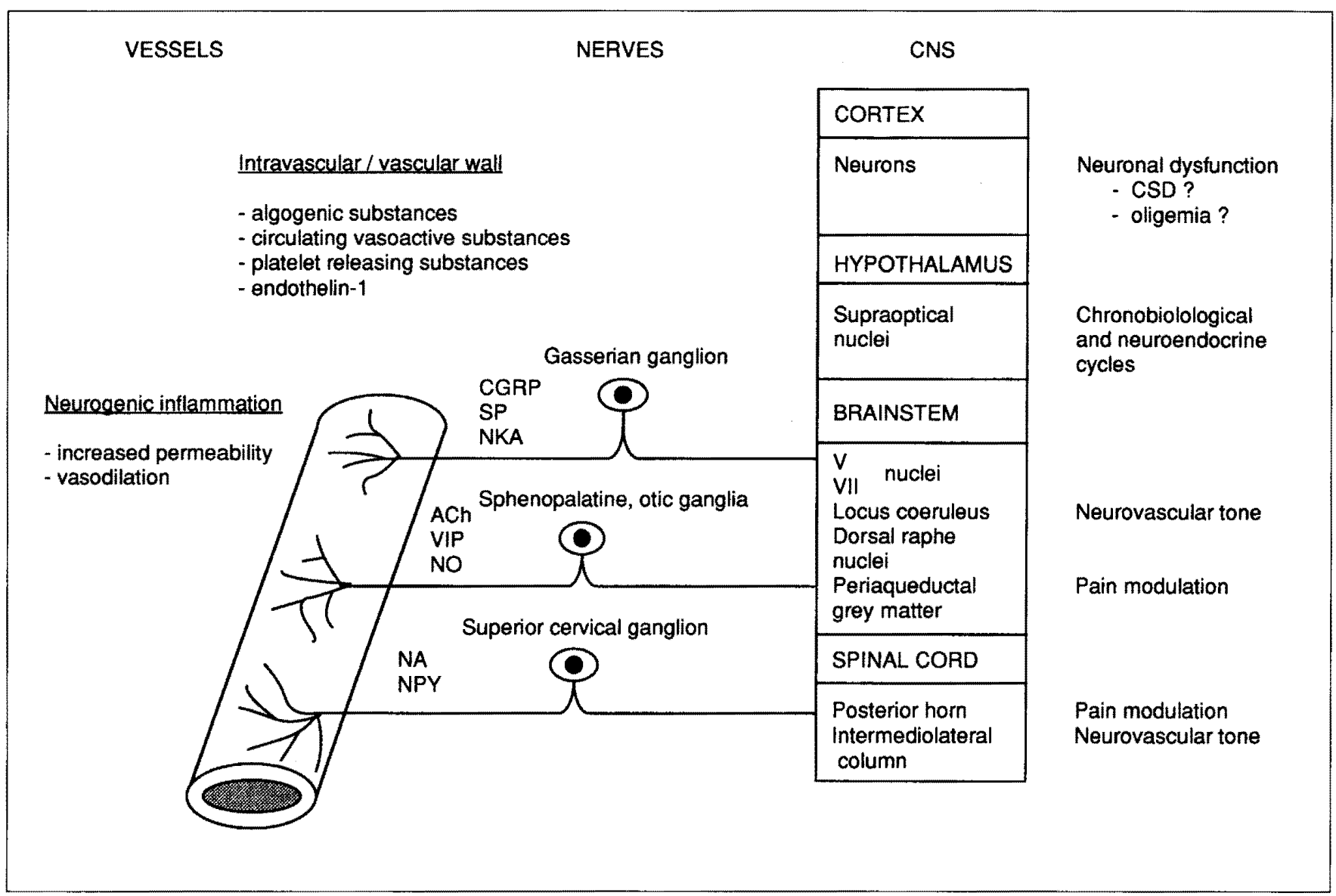

Figure 1) Schematic representation illustrating some relationships between neuroanatomy and biochemistry in vascular headaches. ACh Acetylcholine; CGRP Calcitonin gene-related peptide; CNS Central nervous system; CSD Cortical spreading depression; NA Noradrenaline; NO Nitric oxide; NKA Neurokinin A; NPY Neuropeptide Y; SP Substance P; VIP Vasoactive intestinal peptide

may be transiently compromised in the affected areas. Some of the neuronal effects of the substances released by the platelets (eg, serotonin or thromboxane $\mathrm{A}_{2}$ ) or damaged tissues (eg, glutamate) may be enhanced in this way. These substances may be important in producing a local, transient neuronal dysfunction (perhaps CSD-like) $(76,90)$.

Glutamate, and especially the glutamate agonist $\mathrm{N}$-methylD-aspartate (NMDA), $(93,94)$ may trigger CSD which, in turn, may be blocked by NMDA receptor antagonists ( 95 ). Glutamate levels have been reported to be raised in plasma (96) and CSF (97) during migraine attacks, although different profiles of excitatory amino acid metabolism in migraine with or without aura have recently been found (98).

NMDA receptor activation is important in stimulating the synthesis of nitric oxide (NO) (99), which is not only an important vasodilator, but also a nonsynaptic, diffusible neurotransmitter (100). In endothelial cells, NO is the endothelium-derived relaxing factor released in response to transmitters such as acetylcholine (101). Indeed, several substances putatively involved in neurogenic inflammation and migrainous pain, such as SP and possibly bradykinin, only induce vasodilation if an intact endothelium is present $(102,103)$ because they stimulate release of NO or prostacyclin.

Recently, both NO and CGRP have been implicated in the initial dilation associated with CSD (104). The CSD theory of migraine may therefore provide a reasonable explanation not only for the aura symptoms, but also for the triggering of pain mediators and vascular phenomena. Theoretically, decreased rCBF observed in migraine may be related to transient neuronal inactivation. Whether CSD activates the trigeminovascular system is unknown.

Interestingly, drugs that are effective in the treatment of migraine, such as ergotamine or sumatriptan, have been found to block the neurogenic inflammation caused by the release of vasoactive substances after stimulation of Gasserian cells in experimental animals $(105,106)$. As mentioned earlier, sumatriptan and dihydroergotamine reduce CGRP release to normal levels in migraineurs responsive to the drugs (70). The release of a factor such as NO in affected cranial arteries during neurogenic inflammation may enhance the inflammation (90), but may also reduce local thrombogenesis through anti-aggregation of platelets (107).

Through the trigeminospinal nuclei, connections with many other cranial nerves may be activated. Trigeminal nerve stimulation may cause ipsilateral, intracranial vasodilation, possibly through the parasympathetic part of the facial nerve by co-activation of the superior salivary nuclei.

There may rarely be an association between intracerebral 
hemorrhage and migraine (108-111). It has been suggested that ischemic tissue damage can co-exist with endothelial damage as independent phenomena, resulting in fragile vascular walls. Cerebral bloodflow can be enhanced by trigeminovascular activation in such migraine patients. The vessel wall may then not be resistant enough to bear the extra load, and hemorrhage may ensue.

In this context the coincidental occurrence of cerebral hemorrhage following trigeminal stimulation in connection with dental removal or trigeminal decompression procedures for tic douloureux treatment $(112,113)$ is thought-provoking. It seems that mechanical trigeminal stimulation during surgical procedures may produce intense intracranial vasodilation. This response may be mediated through the connections of this nerve with the parasympathetic part of the facial nerve, and partly through antidromic release of vasoactive substances. If the dilation phase of a migraine attack takes place in a vascular bed with pre-existing neurogenic inflammation, then this combination may explain some of the cryptogenic, intracerebral hemorrhages.

The pain of the migraine attack is frequently ipsilateral to the cerebral hemisphere with the actual neurovascular events, in agreement with ipsilateral trigeminal innervation. However, some patients report bilateral pain. That the trigeminovascular system provides bilateral innervation to the anterior cerebral arteries and superior longitudinal sinus (71) is interesting in that a migrainous process affecting these vascular territories may be perceived as bilateral pain.

There is evidence to suggest an intracranial origin of pain in migraine. However, some patients get relief by pressure towards the superficial temporal artery. This vessel frequently appears dilated and tender on the symptomatic side during migraine attacks $(3,4)$. This dilation, and the pain relief by pressure towards this vessel, strongly suggest a local contribution to the migraine pain that could be due to an extracranial extension of the neurogenic inflammation and an autonomically induced vascular dilation. Convergence of exteroceptive and visceroceptive stimuli at the trigeminal nuclear complex can also explain the referred pain to the superficial region of the head in a way similar to the visceral pain of other origin (56).

CGRP blood levels have been found to be increased in the external jugular vein on the symptomatic side during migraine attacks (69). One possible interpretation of the release of vasoactive substances in extracerebral vascular territories is that it stems from an extracranial extension of the neurogenic inflammation. However, the external jugular vein drains extensive areas, so caution must be exercised in such interpretations. The mediators of pain and tenderness over the superficial temporal artery and surrounding area (114) in the periphery may be factors such as $\mathrm{SP}$ in combination with serotonin and bradykinin.

\section{Serotonin}

Serotonin is a constituent of various nuclei and pathways in the brain. Most 'peripheral' serotonin is found in platelets and the enterochromaffin (argentaffin) cells in the crypts of Lieberkühn. During the initial phase of the migraine attack, serotonin is released from platelets. 5-Hydroxyindolacetic acid, the main catabolite of serotonin, increases in the urine, indicating that serotonin metabolism is accelerated $(115,116)$. The platelets of migraine sufferers seem to show an increased tendency to adhesion and aggregation.

Reserpine may trigger a headache attack (117) that is similar in many ways to migraine (7), probably due to the amine releasing properties of the drug (serotonin and other vasoactive substances). Interestingly, serotonin injected intravenously during a migraine attack usually stops the attack (118).

Because serotonin generally does not cross the BBB, its beneficial effect is thought to be due to its vascular constrictive action on cranial vessels. This is particularly interesting in connection with sumatriptan, which has the ability to stimulate serotonin 1-like receptors selectively. While serotonin per se gives rise to many unwanted side effects because it also stimulates other subclasses of serotonin receptors in the body, sumatriptan should have only selective 'serotonin effects' on certain blood vessels to the head $(119,120)$. Because sumatriptan lacks analgesic properties, its efficacy appears to be achieved through vasoconstriction of the intracranial vessels. Such a model for aborting migraine attacks may be valid if migrainous pain were caused by vasodilation-activating sensory nerves of the trigeminovascular system. Plasma extravasation (as in sterile neurogenic inflammation) and secretion of sensory neuropeptides may stop upon vessel vasoconstriction. Alternatively, or perhaps simultaneously, sumatriptan may act on the serotonin-1 presynaptic receptors of the trigeminal sensory terminals within dural blood vessels, inhibiting the release of sensory neuropeptides and, therefore, the neurogenic inflammation (84) - this is a possibility because dura mater lacks the $\mathrm{BBB}$, which sumatriptan cannot cross under normal circumstances.

Some prophylactic migraine drugs are serotonin-2 antagonists that probably act by modifying neurovascular control and counteracting the platelet release reaction, which is also mediated in part by serotonin-2 receptors. Other drugs, such as acetylsalicylic acid, are probably effective in migraine, not only because of their inhibition of platelet aggregation, but also possibly because of their effect on the arachidonic acid cascade or neurogenic inflammation (121).

In some migraine patients there is a periodic defect in monoamine oxidase (MAO) activity. Because this enzyme plays a role in the catabolism of catecholamines and serotonin, normal MAO activity may be crucial in avoiding attacks triggered by dietetic substances such as tyramine and phenylethylamine, which are not properly metabolized in the absence of MAO activity (122).

Apart from its direct effects on vascular tone, serotonin also plays an important role in central pain control systems (serotonin-1 and -3 receptors) (123). Central depletion of serotonin may be an important factor in the pathogenesis of migraine (124) because the transmission of central pain stimuli may be facilitated in the relative absence of serotonin (125). A possible, beneficial effect of serotonin precursors such as 5-hydroxytryptophan (126) is believed to be due to a "central" repletion of serotonin.

It is highly unlikely - but still possible - that the effect of serotonin in discontinuing the migraine attack is partly due to the correction of a central serotonergic deficit. If neurogenic inflam- 
mation creates leakage through the $\mathrm{BBB}$, it can permit central uptake of serotonin. The local effect of serotonin as a mediator of pain and inflammation may also be an important part of migraine pathogenesis.

\section{Central mechanisms}

The individual susceptibility for migraine is genetically determined, but the nature of the underlying, basic pathophysiological disposition is unknown, as are the details of the process that leads to the full migraine attack.

The attack starts either 'spontaneously' or after exposure to one or more of several possible precipitating factors. It is well known that, for example, cerebral arteriography especially with the old and more toxic contrast media (127), may precipitate an attack with migraine-like qualities (7). Vasodilator agents may do the same, an effect believed to be due to direct action of these factors on the vessel wall. Alternatively, vascular afferents can be activated. Such triggering mechanisms point to a primary vascular origin of the solitary attack. Nevertheless, the natural precipitants for the migraine attack, such as stress, bright light, hunger and sleep, seem to work through the central nervous system (128) and not through the vessels.

The periodicity of spontaneous attacks and their frequent association with physiological cycles (eg, menstruation) suggest a chronobiological dysregulation. This is consistent with a prime role of the hypothalamus in migraine pathophysiology. It is well known that the hypothalamus has important regulatory, autonomic and endocrinological functions. Indeed, the chronobiological pacemaker that determines the timing of physiological events is located in the anterior part of the hypothalamus (suprachiasmatic nuclei). Changes in hypothalamic activity may explain the periodicity, the prodromic symptoms (sleepiness, craving for sweets, mood changes, etc) and even some of the autonomic features that characterize the attack.

The hypothalamus is connected with the periaqueductal grey matter and with other brainstem structures, such as locus coeruleus (LC) and the dorsal raphe nuclei. The periaqueductal grey matter plays an important role in pain modulation, and LC and the dorsal raphe nuclei are thought to have vasoactive effects on cerebral arteries $(129,130)$.

All the aforementioned structures have direct or indirect connections with the trigeminovascular system. Thus, a morphological basis for a primary central origin of the pain of migraine attacks may exist.

According to Lance (130), LC stimulation produces ipsilateral intracranial vasoconstriction and extracranial vasodilation, while the dorsal raphe nucleus and trigeminal nerve stimulations produce intracranial vasodilation. Therefore, changes in the activity of these brainstem structures may reproduce the vascular events that characterize migraine attacks (131). Substrates for a possible neuronal origin of attacks putatively exist. Again, similarity is not the same as identity.

Vascular activity due to dorsal raphe nucleus stimulation may be mediated through a serotonergic pathway, while responses to LC stimulation may be mediated via the direct noradrenergic supply to the intracranial vessels. Connections with the parasympathetic fibres of the facial nerve can represent the dilatory pathway. This latter mechanism may also create vasodilation upon trigeminal nerve stimulation.

Activation of these brainstem structures may be mediated via descendent fibres from the hypothalamus, cerebral cortex and thalamus. These fibres may transmit either the cyclic excitation of the chronobiological pacemaker and neuroendocrine changes, or the central effect of the external stimuli that triggers a migrainous attack. Connections between LC and the intermediolateral column of the spinal cord may facilitate the release of noradrenaline. These connections, or perhaps a serotonin-releasing factor, may stimulate platelet liberation and aggregation.

The periaqueductal grey matter forms part of the pain modulation system. Patients with painful disease who have been treated by electrode implants in the periaqueductal grey matter develop chronic headaches with migrainous elements. These headaches have a strict, temporal relationship with the therapeutic procedure (132). Thus, the periaqueductal grey matter may be an important structure for the genesis of head and facial pain. The region is connected with the midline raphe nuclei.

The midline raphe nuclei inhibit, by a serotonergic descending projection, the transmission of pain impulses at the level of the spinal interneuron. This interneuron has connections with the posterior spinal horn cells (trigeminospinal column at the superior cervical levels). The transfer of impulses is mediated by endorphins. LC may also modulate pain perception by a noradrenergic descendent pathway that reaches the spinal endorphinergic neuron.

All these connections suggest an interaction between the chronobiological pacemaker and the trigeminovascular and pain control systems. One hypothesis (131) is that brainstem structures may give rise to the neurovascular process of migraine - on the one hand the characteristic vascular events may be produced, but on the other hand the pain originating in the cranial arteries may be modulated.

Endorphins exert neurochemical control (modulation) of the central pain transmission. It is probable that both pain tolerance and pain threshold depend on the activity of these endogenous opioids. Patients suffering from migraine have low endorphin levels (133). In the particular case of menstrual migraine, the endogenous opioid tone decreases during the luteal phase (134). The response to pain and the effectiveness of analgesic treatment with morphine are strongly related to the day/night cycle and melatonin plasma levels $(135,136)$. Melatonin is synthesized in the pineal body and is released particularly during the night.

Interestingly, the analgesic response to morphine is at its maximum during the night and correlates with the melatonin plasma levels. Thus, pain tolerance is better at night, possibly due to the rise in endogenous opioid tone and melatonin levels. Moreover, melatonin inhibits prostaglandin $\mathrm{E}_{2}$ synthesis (137), thereby possibly reducing pain modulation.

Melatonin derives from serotonin, and its synthesis is regulated via, for example, sympathetic fibres from the pineal gland. In migraineurs, melatonin levels are low $(138,139)$, which may be due to a chronobiological dysfunction or a sympathetic hypofunction.

There are anatomical connections between hypothalamus and brainstem structures that control both neurovascular tone and 
pain transmission. These pathways may be crucial to the mediation of impulses from centres determining the chronobiological timing of migraine attacks and determining the subjective perception of, and tolerance to, pain.

The autonomic nervous system seems to have a protective function regarding cerebral vessels; the constrictor tone of smooth arterial muscle increases when bloodflow becomes excessive. This reflexogenic sympathetic constriction permits adaptation of vessel calibre to changes of intravascular blood volume (140), which avoids excessive vasodilation and penetration/rupture of the $\mathrm{BBB}$ in the more peripheral arterial branches. Finally, this sympathetic effect may also be important in order to minimize the distant effects of an eventual cerebral artery thrombosis.

The sympathetic trophic effect provides modulation of the vascular response to locally released vasoactive agents, making the vascular response less intense and reducing the effects of the axon reflexes. Thus, a putative unilateral sympathetic deficit can contribute to lateralization of a migraine attack to the more vulnerable side. However, sympathetic deficit may be an epiphenomenon of the migraine process instead of a mechanism that contributes to the attack.

\section{CLUSTER HEADACHE SYNDROME}

$\mathrm{CH}$ predominantly occurs in males. It is characterized by the appearance of unilateral, relatively short-lasting pain attacks localized in or around the orbit. The pain is severe and is typically accompanied by prominent, ipsilateral autonomic signs, such as lacrimation, conjunctival injection and rhinorrhea (for reviews see 141,142 ).

The periodicity of the attacks is a striking feature of this headache. Symptomatic periods may last for one to three months or more; during this time patients have daily or almost daily pain attacks with a relative night predominance. Remission periods may be lacking, either from the very beginning of the disease or after some time with an episodic pattern. In such cases, $\mathrm{CH}$ is to be classified as chronic (2).

Chronic paroxysmal hemicrania $(\mathrm{CPH})$, described by Sjaastad and Dale (143) in 1974, has provisionally been categorized as a subtype of the $\mathrm{CH}$ syndrome (2). It is a headache mainly affecting females, and patients typically have multiple, brief, unilateral attacks, excruciating in intensity (144). The attacks are shorter and more frequent compared with ordinary $\mathrm{CH}$. Indomethacin has an absolute effect in CPH but has little or no effect in ordinary $\mathrm{CH}$. Although most $\mathrm{CPH}$ patients show a chronic pattern, there may also be a remitting stage, which may or may not precede the chronic stage (141). Both the chronic (unremitting) and the remitting stages are thus subtypes of $\mathrm{CPH}$.

Despite the clinical differences between $\mathrm{CH}$ and $\mathrm{CPH}$, both share fundamental characteristics and have been classified as parts of the $\mathrm{CH}$ syndrome; the pathophysiology of the $\mathrm{CH}$ syndrome in this report thus considers the two headaches together.

\section{Vascular mechanisms}

Clinical and supplementary test data suggest a craniovascular involvement in $\mathrm{CH}$ pathogenesis. During the symptomatic period, attacks may be triggered by administration of vasodilating substances such as alcohol, histamine or nitroglycerin $(145,146)$, but only after a delay. Subsequent treatment with vasoconstrictive agents, such as $100 \%$ oxygen or ergotamine, may curb the attack. Compression of the superficial temporal artery may, to some extent, decrease the pain intensity, although patients sometimes report that the orbital pain increases, while temporal pain improves with this manoeuvre (147). Orbital pain may decrease following ipsilateral carotid compression. Such observations indicate that ipsilateral vascular abnormalities are present during attacks.

As far as rCBF is concerned, studies during attacks have shown inconsistent results (24,148-151). Studies by Hørven et al (152), Hørven and Sjaastad (153) and Sjaastad (154,155) demonstrated an ipsilateral increase in intraocular pressure (IOP) and corneal indentation pulse amplitudes during attacks in both $\mathrm{CH}$ and $\mathrm{CPH}$.

Doppler and thermographic studies during attacks have shown results consistent with an increase in bloodflow through the ipsilateral ophthalmic artery (156). In a patient in whom an arteriography was performed during a $\mathrm{CH}$ attack, the internal carotid artery was dilated in its intracavernous portion, and narrowed distal to its exit from the carotid canal (157). The narrowing was believed to be due to a swelling of the arterial wall produced by local inflammation. It should be emphasized that the pulse synchronous changes in arterial diameter were not compensated for in these observations. Comeal temperature was increased on the painful side during symptomatic periods $(153,155)$. Systemic blood pressure does not seem to increase systematically (141). These findings suggest that vascular abnormalities are not only present during the cluster period, but also are probably localized to some extent. Their origin may be between the intracavernous segment of the internal carotid artery and the posterior part of the orbit of the ipsilateral eye ('midline theory') (141).

A 'venous vasculitis' has been claimed to be present in some cases during symptomatic periods of $\mathrm{CH}$ (158), either in ophthalmic veins or in the cavernous sinus. It is unknown whether this putative vasculitis represents a neurogenic inflammation, a recurrent infection process or even a pseudonormal phenomenon. The localization of the pain is consistent with the experimental findings of pain projection mainly to the orbit after stimulation of the cavemous portion of the carotid artery (3).

Particularly in CPH, the sudden and marked rise in IOP during attacks suggests intraocular vasodilation and a local release of vasoactive substances (141). Intraocular release of prostaglandins, SP or CGRP can explain the pain and miosis, as well as the raised IOP. Indeed, the dramatic effect of indomethacin treatment is consistent with the former possibility because this drug is a potent prostaglandin inhibitor. There may, however, be other explanations for the salutary effect of indomethacin in $\mathrm{CPH}$ $(141,155)$. There is little to suggest that increased IOP causes the pain of attack.

\section{Pain mechanisms}

It is widely believed that a local irritative process affects the sensory endings of the trigeminovascular system in $\mathrm{CH}(71$, 159,160 ). Orthodromic activation of $\mathrm{C}$ fibres likely produces the 
pain. Antidromic stimulation can produce a neurogenic inflammation and vasodilation, as may occur in migraine (71), and antidromic release of peptides can contribute to the pain. Brainstem connections or axonal reflexes may, in turn, activate the facial parasympathetic fibres, producing the parasympathetic features.

In $\mathrm{CH}$ sufferers, CGRP and VIP were found to be increased in blood samples taken from the ipsilateral external jugular vein during attacks. The difference was significant compared with controls. Successful treatment of attacks with either oxygen or sumatriptan normalized the CGRP and VIP levels (161). The raised VIP level found during $\mathrm{CH}$ attacks indicates parasympathetic activation, which can be related to trigeminovascular activation by central brainstem connections.

For many years the sympathetic pericarotid plexus has been thought to be compressed between a swollen arterial wall and the bony carotid canal (162). Local compression may explain the sympathetic defect observed during, and partly between, attacks (Horner-like syndrome).

MRI studies have failed to show any abnormality in the cavernous sinus or surrounding area in $\mathrm{CH}$ (163). However, these studies were not made during attacks, and suspicion regarding the cavernous sinus area is still strong.

Single photon emission computed tomography studies performed with ${ }^{67} \mathrm{Ga}$ have shown increased activity in the parasellar region during $\mathrm{CH}$ attacks in $50 \%$ of the patients studied (164). Since ${ }^{67} \mathrm{Ga}$ is concentrated in the tissues affected by inflammatory processes, it has been assumed that an intracavernous neurogenic inflammation could exist.

\section{Autonomic features}

Generally, attacks are accompanied by bilateral autonomic signs, clearly most prominent on the painful side. A relative parasympathetic overactivity during $\mathrm{CH}$ attacks may possibly explain the ipsilateral eye redness, lacrimation and nostril block or rhinorrhea. The high values for IOP and corneal indentation pulse in the symptomatic eye are most likely secondary to intraocular vasodilation. Activation of the trigeminovascular system may produce an axon reflex between the proximal part of the Gasserian ganglion neurons and the sphenopalatine ganglion neurons that are connected with the spinal trigeminal nuclei. Finally, the parasympathetic target organs may be stimulated. Other features, such as the reduced salivation during attacks, are hard to explain on the basis of parasympathetic stimulation (165).

Miosis is largely present also outside attacks, and pupillary asymmetry tends to increase during attack. These features can be caused by diminished sympathetic activity. Pupillometry in $\mathrm{CH}$ indicates a Horner (166) - or, preferably, 'Homer-like' syndrome (167) (the dysfunction underlying the Horner-like picture does not seem to be purely sympathetic and thus the term 'Hornerlike' is preferred) - with a sympathetic deficit of the first or (even more likely) third neuron. Additional studies with evaporimetry (168) have shown that spontaneous and heat-induced sweating is reduced over the medial part of the ipsilateral forehead. Pilocarpine stimulation induces a more marked sweating on the symptomatic versus the nonsymptomatic side. Pupillometric and evaporimetric abnormalities were observed in a clear majority of patients, but not in all. The reason some patients do not exhibit any putative sympathetic deficiency (not even a latent one) is not understood. It may be due to a lesser total impact of the component of the attack (lesser severity, shorter duration or both), for example, that gives rise to the Horner-like picture.

If the deficit were purely sympathetic, it might be due to local compression of the pericarotid sympathetic fibres between a swollen artery and the bony part in the carotid canal (162), or to involvement of the sympathetic fibres by a local, neurogenic inflammation. However, whether this putative sympathetic deficit is a central or peripheral dysfunction is controversial $(165,169)$.

A sympathetic deficit in the anterior part of the hypothalamus may provide an explanation for the sympathetic dysfunction in $\mathrm{CH}(170)$. Most likely the defect is peripheral in nature.

There are clear differences between $\mathrm{CH}$ and $\mathrm{CPH}$ regarding the autonomic pattern. Pupillometry and evaporimetry studies have failed to show a clear and invariable sympathetic defect in $\mathrm{CPH}$. These autonomic differences increase the likelihood that $\mathrm{CH}$ and $\mathrm{CPH}$ are independent nosological entities, despite being currently grouped in the same category of $\mathrm{CH}$ syndrome.

\section{Role of nociceptive substances and SP theory}

Some changes in biogenic amines reportedly may be of possible pathogenetic importance in $\mathrm{CH}$. Thus, serotonin and histamine levels (or their metabolites in blood (171) and occasionally in urine [172]) have been reported to be modestly altered during the symptomatic phase of $\mathrm{CH}$ (171). If anything, these substances may be more important as local algogenic mediators than as important humeral attack triggers in $\mathrm{CH}$.

Sicuteri and co-workers (173) proposed that $\mathrm{CH}$ symptoms may be mediated by antidromic release of SP from activated trigeminal neurons. There is little doubt about the prime effect of SP along with bradykinin and probably serotonin in inducing local pain. In $\mathrm{CH}$, the activation of sensory fibres may be located somewhere along the sensory pathway that carries the stimuli from the ipsilateral eye to the cortex.

Antidromic release of SP can produce miosis and a rise in the IOP (174), both of which appear to be part of CH symptomatology. Capsaicin, a derivative of homovanillic acid found in hot pepper, causes release of neuropeptides, including SP from primary, sensory neurons (175). Repetitive, local, intranasal application of capsaicin depletes stores of SP, and reduces lacrimation, nasal obstruction and rhinorrhea (176). More recent studies have pursued the possibility of capsaicin use as a novel treatment for $\mathrm{CH}(177,178)$.

\section{Chronobiological considerations}

$\mathrm{CH}$ is a striking example of a disorder with a circannual and circadian periodicity. Headache cycles tend to occur once or twice a year (cluster periods or bouts). During the active phase, patients usually have one to three attacks daily, with a nocturnal preponderance. Even more striking is that in some patients, attacks tend to start at the same hour of the day (179). There even seems to be a moderately expressed ultradian rhythm if we consider the relationship of some of the nocturnal attacks with the rapid eye movement (REM) sleep stage (180). The tendency 


\section{TABLE 2}

\section{Headache associated with vascular disorders}

Acute ischemic cerebrovascular disease
Transient ischemic attack
Thromboembolic stroke
Intracranial hematoma
Intracerebral hematoma
Subdural hematoma
Epidural hematoma
Subarachnoid hemorrhage
Unruptured vascular malformation
Arteriovenous malformation
Saccular aneurysm

Arteritis

Giant cell arteritis

Other systemic arteritides

Primary intracranial arteritis

Carotid or vertebral artery pain

Carotid or vertebral dissection

Carotidynia

Postendarterectomy headache

Venous thrombosis

Arterial hypertension

Acute pressor response to exogenous agent

Pheochromocytoma

Malignant hypertension

Pre-eclampsia and eclampsia

Adapted from reference 2

towards a 'REM-locked' pattern may be even more marked in $\mathrm{CPH}$ (135). Indeed, CPH is included in the group of sleep disorders known as parasomnias (181). This suggests that in $\mathrm{CH}$ syndrome there is alteration of the biological clock or a prime effect of the chronobiological structures determining the timing of the symptomatic periods and individual attacks, produced by essentially different mechanisms. If these assumptions are correct, the hypothalamus may be a crucial anatomical structure in the pathogenesis of $\mathrm{CH}$ (182). This applies to the 'preparatory' stage. Once an attack has started, 'peripheral' mechanisms seem to predominate. Hypothalamic connections with brainstem structures that regulate pain transmission or craniovascular tone have been discussed earlier.

Periodic reactivation of a chronic infection has been proposed as a mechanism that can trigger cluster periods $(183,184)$. Herpes simplex virus has a well known neurotrophic profile and is periodically activated. This virus may produce a ganglionitis affecting the Gasserian and/or sphenopalatine ganglia, and this process may be cyclically reactivated. A relationship between $\mathrm{CH}$ and lymphogranulomatous meningitis (185) or aseptic meningitis (186) has even been proposed.
There are several common examples of the relationship between the neuroendocrine system and immunology. The menstrual herpes virus reactivation is one of the best known. In fact, immunological activity also has circannual and circamenstrual waxing and waning cycles for macrophage and lymphocyte functions. A remote possibility is that a neuroimmunological system dysfunction plays a role in determining the timing of $\mathrm{CH}$ bouts (159). Whether, and to what extent, a direct hypothalamic stimulus or an infection reactivation triggers the bout is unknown.

Hypoventilation during REM sleep, sleep apnea or both may play a role for the sleep-related attacks. An increased incidence of sleep apnea and a tendency for $\mathrm{CH}$ patients to suffer attacks at high altitude have been reported (187), although the present authors are not aware of any comprehensive study concerning high altitude and an increased attack tendency. However, oxygen inhalation is frequently effective as a treatment for single attacks, and Kudrow (188) has hypothesized that $\mathrm{CH}$ pathogenesis is intimately linked with respiratory dysregulation by sympathetic inhibition and parasympathetic disinhibition of carotid body autonomic tone.

Chemoreceptors located in the carotid body physiologically respond to variations in blood oxygen, carbon dioxide and $\mathrm{pH}$, and influence the brainstem respiratory regulatory system. This regulatory system then adjusts ventilation to maintain normal blood gas levels. In $\mathrm{CH}$, hypoxia during sleep may induce a hyperactivation (possibly denervation supersensitivity) of the chemoreceptors and consequently a stimulation of the respiratory centre with ensuing ventilatory drive. However, because the hypothalamus is the major autonomic centre, the primary dysfunction may still be located in that area.

During REM sleep, respiration is under the direct influence of the forebrain, the chemoreceptors playing only a secondary role restricted to the brief periods of REM phasic events. Hypoxia is a poor stimulus for activation of chemoreceptors during sleep, at which time the main stimulus for the ventilatory drive seems to be carbon dioxide.

More recent studies have demonstrated that daytime hypoxia does not seem to produce $\mathrm{CH}$ attacks $(189,190)$. Sleep-related hypoxia may act as a contributory factor to REM-related $\mathrm{CH}$ attacks rather than being the sole trigger. The most current study results emphasize that hypoxia is of little or no significance for the generation of solitary attacks.

\section{HEADACHE ASSOCIATED WITH VASCULAR DISORDERS}

Generally, headaches may occur in patients with clinical and supplementary test evidence indicating a vascular disorder.

According to the IHS classification (2), a new form of headache (including migraine, tension-type headache and $\mathrm{CH}$ ) that develops in close temporal relation with a vascular disorder is to be classified in one of the latter groups, although a causal relationship is not necessarily implied. If the vascular disease only produces a worsening pre-existing headache, the headache should still be classified according to its previous form.

Cerebrovascular disease, in particular bleeding, is frequently accompanied by headache or facial pain (Table 2 ). 
Headache associated with ischemic cerebrovascular disease Approximately $30 \%$ of patients having ischemic cerebrovascular episodes of various types report headache among the initial symptoms (191-198). Headache is more frequent with infarcts in the cortical versus in the deep layers (199), and is only rarely associated with lacunar infarcts. Thrombosis and transient ischemic attacks produce headache more frequently than embolism. Generally, the headache of an ischemic episode is ipsilateral to the lesion, although basilar artery ischemia may produce bilateral headache. With carotid artery ischemic events, the headache (193) is generally reported in the anterior regions, while in vertebrobasilar ischemia, the pain is located posteriorly. Most headaches associated with cerebral ischemia are of moderate intensity and the pain is throbbing or steady (193).

Information concerning the pathophysiology of these ischemic headaches is scarce. The temporal relationship with the ischemic episode and the unilaterality of the pain suggest a local origin of the pain in the vessel(s) affected or the area perfused. The hypoxia or the metabolic products released by ischemic tissues may be of importance for activation of sensory fibres. It is also feasible that these fibres are stimulated in a mechanical way by the thrombotic or embolic arterial occlusion. Intracerebral arterioles (penetrators) are not innervated and are thus insensitive to pain (200). In the rare cases of headache associated with lacunar infarcts, pain may arise from occlusion of the stem of a major cerebral artery, resulting in downstream ischemia and distal deep infarct. It has been proposed (193) that serotonin and prostaglandins are released by platelets, act on the vascular wall and contribute to the pain. The ischemic process and platelet activation occur in all patients, but only $30 \%$ of them report headache; perhaps headache associated with cerebral ischemia is characterized by vascular pain susceptibility so that the pain process is easily activated by hypoxia.

Can such a predisposition be part of a 'migrainous diathesis'? Migraineurs may exceptionally present a cerebral infarction as a complication of a migraine attack. In such cases, cerebral hypoperfusion might have been intense enough to produce ischemic lesions. Alternatively, an additional factor may be necessary to produce the infarct.

It is important to note that migraine does not produce cerebral infarct via production of atherosclerotic lesions and that atherosclerosis does not produce headache.

Migraine and cerebrovascular ischemic disease are frequent disorders. Cerebral ischemia may trigger mechanisms supposedly typical of migraine, but this does not imply that headache associated with cerebral ischemia is a migraine-like process. These headaches and others probably use the trigeminovascular system as a final common pathway of pain expression, the differences being the causative factors and the 'neural constitution'.

\section{Headache associated with spontaneous dissection of intra-and extracranial arteries}

The dissection of intra- and extracranial arteries causes approximately $2 \%$ of all ischemic cerebrovascular episodes and up to $5 \%$ of the infarcts in young people. Headache is a frequent symptom in this disorder and typically precedes the onset of the ischemic event. Awareness of the important clinical charac- teristics of this disorder may lead to alertness regarding the insidious onset of cerebral ischemia, so that the damage can be minimized.

Headache starts abruptly and is always ipsilateral to the dissection. Pain is referred to the anterior region of the head when the affected artery is the internal carotid artery or some of its principal branches. Dissection of the vertebral artery produces occipital and neck pain. The headache is moderate to severe and is frequently steady in character, although it is sometimes perceived as throbbing $(201,202)$. Dissection frequently takes place after traumatic events, but it may also be spontaneous. In some incidents, it reportedly is caused by arteriopathy with a predisposition to spontaneous dissection (203). The occurrence of this disorder among migraineurs (202-207), combined with the observed improvement of the pain with treatment also effective in migraine (methysergide, prednisone), suggests - but does not prove - that both share some pathophysiological mechanisms (201).

When dissection is extracranial, pain precedes the ischemic event by hours or days. The ischemic event in these cases may be embolic. In intracranial dissection, headache is severe and more immediately before the ischemia (202).

The localization and temporal relationship of headache and arterial dissection suggest a local origin of the pain. The dissecting hematoma produces a distension of the vessel wall and may lead to a traumatic stimulation of arterial wall sensory endings. Pain in these cases, therefore, is believed to be mechanically triggered. The onset of headache antedating the cerebral ischemia seems to rule out any cerebral, biochemical mediation of the pain.

\section{Carotidynia}

Pain in the face, neck, ocular area or head triggered by pressure over the internal carotid artery is called carotidynia. The artery may be dilated in addition to being tender. Carotidynia may be a sign accompanying the migraine attack, or it may be an independent syndrome $(208,209)$. In its usual form, carotidynia seems to be a self-limiting disorder with one, single, short pain period (mean duration is 12 days according to Roseman [210]).

The clinical manifestation of primary carotidynia is a unilateral, protracted pain over the neck, inferior part of the face or the head $(210,211)$. An episodic variety has also been described with a more intense and pulsatile pain, with a duration of minutes to hours (209). During the symptomatic periods, the internal carotid artery is particularly sensitive to local pressure. This manoeuvre evokes the characteristic pain that is referred to neck and face.

Primary carotidynia responds to the same treatment as migraine. However, it may be necessary to add corticosteroids at the beginning of a treatment course to obtain successful prophylactic treatment with antimigraine drugs. The frequent association between migraine and carotidynia and the pharmacological response to migraine drugs may point to some common mechanisms of pain.

\section{Headache associated with cerebral hemorrhagic disease and hypertension}

Headache may be a symptom of cerebral hemorrhagic episodes. Almost all SAH patients and more than half the patients with parenchymal hemorrhage report headache as an initial symptom. 
In many cases the head pain precedes the clinical bleeding. SAH produces a severe, holocranial headache with abrupt onset in most cases. Usually the headache is accompanied by nausea, vomiting and neck stiffness. The pathophysiology of the pain is meningeal irritation from the bleeding or possibly intracranial hypertension produced by a sudden increase in intracranial volume (212).

Rupture of an aneurysm or an arteriovenous malformation (AVM) is the usual cause of SAH (213). In aneurysmal rupture, about $50 \%$ of patients have had headache days or even weeks before rupture $(212,214)$. The headache may even be caused by a minor leakage. In some cases with localized headache (212), the underlying mechanism may be the focal, vascular pain produced by the local irritation of the leakage. 'Thunderclap headache' $(215,216)$ is an acute, severe episode of head pain that at times is produced by an unruptured aneurysm. In such cases, the mechanism of pain may be related to intramural bleeding, intrasaccular thrombosis or aneurysmal expansion (217). If large enough, the aneurysm may, on rare occasions, produce chronic headache by a mass effect on the adjacent structures (217).

Vasospasm associated with SAH may produce vascular damage, affecting the three layers of the vessel wall. Such changes are smooth muscle necrosis, vacuolar degeneration with intimal swelling, cell desquamation and fibrosis of the endothelium, and edema of the adventitia $(56,218)$. Under such conditions, a thrombus can build up because loss of the endothelial cells leaves the subendothelial collagen uncovered. Collagen is a potent stimulus for platelet adhesion and aggregation to the wall of the damaged vessel. In addition, thromboplastin released by the vascular lesion triggers the cascade of intravascular fibrin formation. Fibrin and the platelet clot will contribute to the eventual formation of a thrombus. A thrombotic process may occlude the damaged vessel, with ensuing cerebral ischemia. As discussed earlier, there is accumulating evidence to suggest that the trigeminovascular system is activated during sustained vasospasm to restore vascular tone, and CGRP has been implicated in a number of studies (64-67). Preliminary results suggest that CGRP could be effective in counteracting vasospasm following SAH (219).

Arteriovenous malformations may produce headache without

\section{REFERENCES}

1. Ad Hoc Committee on Classification of Headache: Classification of headache. JAMA 1962;179:717-8.

2. Headache Classification Committee of The International Headache Society. Classification and diagnostic criteria for headache disorders, cranial neuralgias and facial pain. Cephalalgia 1988;7 (Suppl 8):1-96.

3. Wolff HG. Headache and Other Head Pain. New York: Oxford University Press, 1963.

4. Graham JR, Wolff HG. Mechanism of migraine headache and action of ergotamine tartrate. Arch Neurol Psychiatr 1938;39:737-63.

5. Sicuteri $F$. Headache as metonymy of non-organic central pain. In: Sicuteri F, ed. Headache: New Vistas. Florence: Biomedical Press, 1977:19-67.

6. Appenzeller $O$. Pathogenesis of vascular headache of the migraine type: the role of impaired central inhibition. Headache 1975;15:177-9.

7. Sjaastad O. Vascular and biochemical changes in migraine. In: Saxena PR, ed. Migraine and Related Headaches. Rotterdam: Erasmus University, 1975:55-69.

8. Skinhøj E. Hemodynamic studies within the brain during migraine. Arch Neurol 1973;29:95-8. rupture in about $20 \%$ of cases $(220)$. These headaches are sometimes episodic and clinically similar to migraine. In most cases, the migraine-like headache steadily recurs on the side of the AVM (221), and sometimes the aura symptoms correlate with AVM topography. Thus, an interdependence of both disorders has been claimed (222). However, it has not been convincingly demonstrated that there is any type of causal relationship between AVM and migraine. A coexistence of both disorders can even occur by chance (223).

Parenchymal hemorrhage is usually due to vessel wall abnormalities generated by hypertension. Deep artery wall degeneration causes the formation of microaneurysms that may eventually rupture. Parenchymal hemorrhage causes headache that is insidious in onset, is frequently unilateral (192) and may eventually become severe. The mechanism of pain production is probably a distension and compression of sensitive intracranial structures caused by the accumulation of blood.

Classically, chronic hypertension has been thought to produce headache. However, several studies have failed to provide proof (224-227), Most patients with chronic hypertension report headache only when their blood pressure reaches high levels, such as occurs in patients with hypertensive encephalopathy and, occasionally, pheochromocytoma. Headache occurs in $75 \%$ of the cases of hypertensive encephalopathy. The underlying mechanisms may be intracranial hypertension secondary to the vasodilation and an increase in vascular permeability, with edema tendency. This may be the sequence of events when vascular autoregulation is lost as a result of dramatically increased blood pressure levels $(228,229)$.

About $80 \%$ of pheochromocytoma patients report headache during exacerbations of the disease $(230,231)$. In these cases, headache is rapid in onset, severe, throbbing (230) and holocranial. Typically, the pain episodes are short-lasting (less than $1 \mathrm{~h}$ ) in most patients. The mechanism underlying these headaches is probably the abrupt increase in blood pressure due to the pressor effect of noradrenaline and adrenaline (231).

Although our understanding of the mechanisms underlying vascular pain is increasing there are still many obscure areas. Knowledge within this field is expected to increase enormously in the foreseeable future.

9. Olesen 3, Larsen B, Lauritzen M. Focal hyperaemia followed by spreading oligemia and impaired activation of rCBF in classic migraine. Ann Neurol 1981:9:344-52.

10. Lauritzen $M$, Olsen TS, Lassen NA, Paulson OB. Changes in regional cerebral blood flow during the course of classic migraine attacks. Ann Neurol 1983;13:633-41.

11. Lauritzen $M$, Olsen J. Regional cerebral flow during migraine attacks by Xenon- 133 inhalation and emission tomography. Brain 1984; 107:447-61.

12. Leão AAP. Spreading depression of activity in cerebral cortex. J Neurophysiol 1944;7:359m90.

13. Milner PM. Note on a possible correspondence between the scotomas of migraine and spreading depression of Leão. Electroenceph Clin Neurophysiol 1958;10:705.

14. Skyhöj Olsen T, Lassen NA. Blood flow and vascular reactivity during attacks of classic migraine. Limitations of the $\mathrm{Xe}-133$ intraarterial technique. Headache 1989;29:15-20.

15. Skyhöj Olsen T, Friberg L, Lassen NA. Ischemia may be the primary cause of the neurologic deficits in classic migraine. Arch Neurol 1987;44:156-61.

16. Skyhöj Olsen T, Larsen B. Bech Skriver E, Lassen NA. Focal cerebral 
ischemia measured by the intra-arterial 133-Xenon method. Stroke $1981: 12: 736-46$

17. Olsen ST. Spreading oligemia in the migraine aura - most likely an artifact due to scattered radiation. Cephalagia 1993;13:86 8.

18. Friberg L, Olesen J, Lassen NA, Olsen ST, Karle A. Cerebral oxygen extraction, oxygen consumption, and regional cerebral blood flow during the aura phase of migraine. Stroke 1994;25:974-9.

19. Friberg L, Skyhöj Olsen T, Roland PE, Lassen NA. Focal ischemia caused by instability of cerebral tone during attacks of hemiplegic migraine: a regional cerebral blood flow study. Brain 1987;110:917-34.

20. Skyhöj Olsen T. Migraine with and without aura: The same disease due to cerebral vasospasm of different intensity. A hypothesis based on rCBF studies during migraine. Headache 1990:30:269-72.

21. Olesen J, Friberg L, Skyhöj Olsen T, et al. Timing and topography of cerebral blood flow, aura and headache during migraine attacks. Ann Neurol 1990;28:791-8.

22. Battistella PA, Ruffilli R, Dalla Pozza F, et al. 99 mTe HM-PAO SPECT in pediatric migraine. Headache 1990;30:646-9

23. Andersen AR, Friberg L, Skyhöj Olsen T, Olesen J. Delayed hyperemia following hypoperfusion in classic migraine. Arch Neurol 1988:45:154-9.

24. Sakai F, Meyer JS. Regional cerebral hemodynamics during migraine and cluster headache measured by the 133-Xe mhalation method. Headache 1978; 18:122 32

25. Drake ME, Pakalnis A, Padamadan H. Long-latency auditory event related potentials in migraine. Headache $1989 ; 29: 23840$.

26. Nyrke T, Kangasniemi $P$, Lang $H$. Transient asymmetries of steady-state visual evoked potentials in classic migraine. Headache 1990;30:133-7.

27. Schlake HP, Grotemeyer KH, Hofferberth B, Husstedt IW, Wiesner S. Brainstem auditory evoked potentials in migraine - evidence of increased side differences during the pain-free interval. Headache 1990; 30:129-32.

28. Jacome DE, Leborgne J. MRI studies in basilar artery migraine. Headache 1990;30:88-90.

29. Ziegler DK, Batnitzky S, Barter R, McMillan JH. Magnetic resonance image abnormality in migraine with aura. Cephalaigia 1991;11:147-50.

30. Ferbert $A$, Busse D, Thron A. Microinfarction in classic migraine? A study with magnetic resonance imaging findings. Stroke $1991 ; 22: 1010-4$

31. Igaraski H, Sakai F, Kan S, Okada J, Tazaki Y. Magnetic resonance imaging of the brain in patients with migraine. Cephalalgia 1991;11:69-74.

32. Welch KMA, Levine SR, D'Andrea G, Helpern JA. Brain pH in migraine: An in vivo phosphorus-31 magnetic resonance spectroscopy study. Cephalalgia 1988;8:273-7.

33. Welch KMA, Levine SR, D'Andrea $G$, Schultz LR, Helpern JA. Preliminary observations on brain energy metabolism in migraine studied by in vivo phosphorus-31 NMR spectroscopy. Neurology 1989;39:538-41.

34. Montagna $P$, Cortelli $P$, Barbiroli B. Magnetic resonance spectroscopy studies in migraine. Cephalatgia 1994;14:184-93.

35. Ramadan NM, Halvorson H, Vande Linde A, Levine JR, Helpern JA, Welch KMA. Low brain magnesium in migraine. Headache $1989 ; 29: 590-3$.

36. Welch KMA, Barkley GL, Tepley N, Ramadan NM. Central neurogenic mechanisms of migraine. Neurology 1993,43:S21-5.

37. Barkley GL, Tepley N, Simkins R, Moran J, Welch KMA. Neuromagnetic fields in migraine. Preliminary findings. Cephalalgia 1990:10:171-6.

38. Ranson R, Igarashi H, MacGregor EA, Wilkinson M. The similarities and differences of migraine with aura and migraine without aura: A preliminary study. Cephalalgia 1991;11:189-92.

39. Tinuper $P$, Costelli $P$, Sacquegna $T$, Lugaresi E. Classic migraine attack complicated by confusional state: EEG and CT study Cephalalgia 1985:5:63 8

40. Lude E, Bo E, Sicuro L, Comitangelo R, Campana M. Sustained visual aura: A totally new variation of migraine. Headache 1991:31:582-3.

41. Frequin STFM, Linssen WHJP, Pasman JW, Hommes OR, Merx HL. Recurrent prolonged coma due to basilar artery migraine. A case report. Headache 1991;31:75-81.

42. Welch KMA. Migraine-related stroke in the context of the International Headache Society Classification of Head Pain. Arch Neurol 1990;47:458-62.
43. Rothrock JF, Walicke P, Swenson MR, Lyden PD, Logan WR. Migrainous stroke. Arch Neurol 1988;45:63-7.

44. Deshimukh $S$, Meyer J. Cyclic changes in platelet dynamics and the pathogenesis and prophylaxis of migraine. Headache 1977;17:101-8.

45. Silvestrine M, Cupini LM, Matteis M, De Simone R, Bernardi G. Migraine in patients with stroke and antiphospholipid antibodies. Headache 1993;33:421-6.

46. Levine $S R$, Joseph $R, D^{\prime}$ Andrea $G$, Welch KMA. Migraine and the lupus anticoagulant. Cephalagia 1987;7:93-9.

47. Sinclair W. Dissecting aneurysm of the middle cerebral artery associated with migraine syndrome. Am J Pathol 1953;29:1083.

48. Gamberini G, D'Alessandro R, Labriola E, et al. Further evidence on the association of mitral valve prolapse and migraine. Headache $1984: 24: 39-40$

49. Spaccavento LJ, Solomon GD. Migraine as an etiology of stroke in young adults. Headache 1984:24:19-22.

50. Couch JR, Hassanein RS. Headache as a risk factor in atherosclerosis related diseases. Headache 1989:29:49-54.

51. Schulman EA, Hershey B. An unusual angiographic picture in status migrainosus. Headache 1991;31:396-8.

52. Pfaffenrath V, Kommissari I. Poilman W, Kaube H, Rath M Cerebrovascular risk factors in migraine with prolonged aura and without aura. Cephalalgia 1991:11:257-61

53. Iñiguez $\mathrm{C}$, Pascual $\mathrm{C}$, Pardo $\mathrm{A}$, Martinez Castrillo JC, Alvarez-Cermeno JC. Antiphospholipid antibodies in migraine. Headache 1991;31:666 8,

54. Henrich JB. The association between migraine and cerebral vascular events: an analytical review. J Chron Dis 1987;40;329-6.

55. Gómez CR, Gómez SM, Puricelli MS, Malik MM. Transcranial doppler in reversible migrainous vasospasm causing cerebellar infarction; $A$ report of a case. Angiology 1991;42:152-6.

56. Solomon $S$, Lipton RB, Harris PY. Arterial stenosis in migraine spasm or arteriopathy. Headache 1990;30:52-61.

57. Spierings ELH. Angiographic changes suggestive of vasospasm in migraine complicated by stroke. Headache 1990;30:727-8.

58. Yanagisawa $\mathrm{M}$, Kurihara $\mathrm{H}$, Kimura S, et al. A novel potent vasoconstrictor peptide produced by vascular endothelial cells. Nature 1988:332:411-5.

59. Suzuki R, Masoaka H, Hirata $X$, Marumo F, Isotani E. Harakawa K. The role of endothelin-1 in the origin of cerebral vasospasm in patients with aneurysmal subarachnoid hemorrhage. I Neurosurg 1992;77:96-100.

60. Ziv I, Fleminger G, Djaldetti R, Achiron A. Melamed E, Sokolovsky $M$. Increased plasma endothelin- 1 in acute ischemic stroke. Stroke $1992 ; 23: 1014-6$.

61. Färkkilä M, Palo J, Sajonmaa O, Fyrhquist F. Raised plasma endothelin during acute migraine attack. Cephalalgia 1992;12:383-4.

62. Gallai V, Sarchielli P. Firenze $C_{x}$ et al. Endothelin-1 in migraine and tension-type headache. Acta Neurol Scand 1994;89:47-55.

63. Linnik MD, Sakas DE, Uhl GR, Moskowitz MA. Subarachnoid blood and headache: Altered trigeminal tachykinin gene expression. Ann Neurol 1989;25:179-84.

64. Juul R, Edvinsson L, Gisvold SE, Ekman R, Brubakk AO, Fredriksen TA. Calcitonin gene-related peptide-LI in subarachnoid haemorrhage in man. Signs of activation of the trigemino-cerebrovascular system? Br I Neurosurg 1990;4:171-9.

65. Juul R. Hara H, Gisvold SE, et al. Alterations in perivascular dilatory neuropeptides (CGRP, SP, VIP) in the extemal jugular vein and in cerebrospinal fluid following subarachnoid haemorthage in man. Acta Neurochir (Wien) 1995; 132:32-41.

66. Edvinsson L, Ekman R, Jansen I. McCulloch J, Mortensen A. Uddman $R$. Reduced levels of calcitonin gene-related peptide-like immunoreactivity in human brain vessels after subarachnoid haemorrhage. Neurosci Lett 1991;121:151-4.

67. Edvinsson L, Juul R, Jansen I. Perivascular neuropeptides (NPY, VIP CGRP and SP) in human brain vessels after subarachnoid haemorrhage. Acta Neurol Scand 1994:90:324-30.

68. Moskowitz MA, Reinhard JF Jr, Romero J, Melamed E, Pettibone DJ. Neurotransmitters and the fifth nerve: is there a relation to the headache phase of migraine? Lancet 1979; 1 : $883-4$.

69. Goadsby PJ, Edvinsson L, Ekman R. Vasoactive peptide release in the extracerebral circulation of human during migraine headaches. Ann Neurol 1990;28:183-7.

70. Goadsby PJ, Edvinsson L. The trigeminovascular system and migraine: Studies characterizing cerebrovascular and neuropeptide changes seen in humans and cats. Ann Neurol 1993;33:48-56. 
71. Moskowitz MA. Basic mechanisms in vascular headache. Neurol Clin $1990 ; 8: 801-15$

72. Goadsby PJ, Zagami AS, Lambert GA. Neural processing of craniovascular pain: A synthesis of the central structures involved in migraine. Headache 1991;31:365-71.

73. Uddman R, Edvinsson L. Neuropeptides in the cerebral circulation. Cerebrovase Brain Metab Rev 1989; 1:230-52.

74. Hardebo JE. Why and how a cortical excitatory wave may initiate the aura and headache. Headache 1991;31:213-21.

75. Benveniste H, Drejer J, Schousboue A, Diemer NH. Elevation of the extracellular concentrations of glutamate and aspartate in rat hippocampus during transient cerebral ischemia monitored by intracerebral microdialysis. J Neurochem 1984;43:1369-74.

76. Siesjö BK, Bengtsson F. Calcium fluxes, calcium antagonists, and calcium-related pathology in brain ischemia, hypoglycemia, and spreading depression: A unifying hypothesis. J Cereb Blood Flow Metab 1989;9:127-40.

77. Rothman SM, Olney JW. Glutamate and the pathophysiology of hypoxic-ischemic brain damage. Ann Neurol 1986;19:105-11.

78. Gilman AG. G proteins. Annu Rev Biochem 1987;56:615-49.

79. Axelrod J. Receptor-mediated activation of phospholipase $\mathrm{A}_{2}$ and arachidonic acid release in signal transduction. Biochem Soc Transact 1990;18:503-7.

80. Rana RS, Hokin LE. Role of phosphoinositides in transmembrane signaling. Physiol Rev 1990;70:115-64.

81. Berridge MJ, Irvine RF. Inositol trisphosphate, a novel second messenger in cellular signal transduction. Nature (Lond) 1984:312:315-21.

82. Taylor CW. Receptor regulation of calcium entry. Trends Pharmacol Sci 1987;8:79-80.

83. Guillon G, Mouillac B, Savage AL. Modulation of hormone-sensitive phospholipase C. Cell Signal 1992;4:11-23.

84. Moskowitz MA. The visceral organ brain: Implications for the pathophysiology of vascular head pain. Neurology 1991;41:182-6.

85. Needleman P, Turk J, Jakschik BA, Morrison AR, Lefkowith JB Arachidonic acid metabolism. Annu Rev Biochem 1986;55:69 102.

86. Yasuda H, Kishiro K, Izumi N, Nakanishi M. Biphasic liberation of arachidonic and stearic acids during cerebral ischemia. I Neurochem 1985;45:168-72.

87. Rotman EI, Brostrom CO. Inhibition of protein synthesis in intact mammalian cells by arachidonic acid. Biochem $J$ $1992 ; 282: 487-94$.

88. Carlson LA, Ekelund L-G, Orö L. Clinical and metabolic effects of different doses of prostaglandin $E_{1}$ in man. Acta Med Scand $1968 ; 183: 423-30$.

89. Parantainen J, Vapaatalo H, Hokkanen E. Relevance of prostaglandins in migraine. Cephalalgia 1985;5(Suppl 2):93-7.

90. Moskowitz MA. The neurobiology of head pain. Ann Neurol $1984 ; 16: 157-68$.

91. Johnson AK, Erdos EG, Release of histamine from mast cells by vasoactive peptides. Proc Soc Exp Biol Med 1973;142:1252-6.

92. Linnik MD, Moskowitz MA. Identification of immunoreactive substance $\mathrm{P}$ in human and other mammalian endothelial cells. Peptides $1989 ; 10: 957-62$.

93. Van Harreveld A. Compounds in brain extracts causing spreading depression of cerebral cortical activity and contraction of crustacean muscle. I Neurochem 1959;3:300-15.

94. Curtis DR, Watkins JC. Analogues of glutamic acid and gamma-amino n-butyric acids having potent actions on mammalian neurones. Nature 1961;191:1010-1.

95. Lauritzen M, Hansen AJ. The effect of glutamate receptor blockade on anoxic depolarization and cortical spreading depression. J Cereb Blood Flow Metab 1992;12:223-9.

96. Ferrari MD, Odink J, Bos KD, Malessy MJA, Bruyn GW. Neuroexcitatory plasma amino acids are elevated in migraine. Neurology 1990;40;1582 6.

97. Martínez F, Castillo J, Rodríguez JR, Leira R, Noya M. Neuroexcitatory amino acid levels in plasma and cerebrospinal fluid during migraine attacks. Cephalalgia 1993;13:89-93.

98. Cananzi AR, D'Andrea G, Perini F, Zamberlan F, Welch KMA. Platelet and plasma levels of glutamate and glutamine in migraine with and without aura. Cephalalgia 1995;15:132-5.

99. Garthwalte J. Nitric oxide synthesis linked to activation of excitatory neurotransmitter receptors in the brain. In: Moncada S, Higgs EA, eds. Nitric Oxide From L-arginine: A Bioregulatory System. Amsterdam: Elsevier, 1990:115-37.
100. Moncada S, Palmer RMJ, Higgs EA. Nitric oxide: Physiology, pathophysiology, and pharmacology. Pharmacol Rev 1991;43:109-42.

101. Furchgott RF, Zawadski JV. The obligatory role of endothelial cells in the relaxation of smooth muscle by acetylcholine. Nature (Lond) 1980;288:373-6

102. Cherry PD, Furchgott RF, Zawadski JV, Jothianandan D. Role of endothelial cells in relaxation of isolated arteries by bradykinin. Proc Soc Acad Sci USA 1982;792:2106-10.

103. Zawadski JV, Furchgott RF, Cherry PD. The obligatory role of endothelial cells in the relaxation of arterial smooth muscle by substance P. Fed Proc 1981;40:689.

104. Wahi M, Schilling L, Parsons AA, Kaumann A. Involvement of calcitonin gene-related peptide (CGRP) and nitric oxide (NO) in the pial artery dilatation elicited by cortical spreading depression. Brain Res 1994;637:204-10

105. Sato K, Markowitz S, Moskowitz MA. Ergot alkaloids block neurogenic extravasation in dura mater: Proposed action in vascular headache. Ann Neurol 1988;24:732-7.

106. Buzzi MG, Moskowitz MA. The antimigraine drug, sumatriptan (GR43175), selectively blocks neurogenic plasmsa extravasation from blood vessels in dura mater. Br J Pharmacol 1991;99:202-6.

107. Gryglewski RJ, Vane JR. A possible role of endothelial vasorelaxants in the pathogenesis of migraine. In: Sandler M, et al, eds. Migraine: A Spectrum of Ideas. New York: Oxford University Press, 1990:51-8.

108. Cole A, Aube M. Late-onset migraine with intracerebral hemorrhage: A recognizable syndrome. Neurology 1987;37(Suppl 1):238.

109. Caplan L. Intracerebral hemorrhage revisited. Neurology $1988: 38: 624-7$.

110. Shuaib A, Metz L, Hing T. Migraine and intracerebral hemornage. Cephalalgia 1989;9:59 61.

111. Gautier JC, Majdalami A, Juillard JB, Carmi AR. Hemorragies cerebrales au cours de la migraine. Rev Neurol 1993;149:407-10.

112. Barbas N, Caplan L, Baquis G, Adleman L, Moskowitz MA. Dental chair intracerebral hemorrhage. Neurology 1987;37:511-2.

113. Haines $\$$, Maroom J, Jannetta P. Supratentorial intracerebra hemornage following posterior fossa surgery. J Neurosurg 1978;49:881-6.

114. Jensen $K$, Tuxen C, Pedersen-Bjergaard V, Jansen I. Pain, tendemess, wheal and flare induced by substance $P$, bradykinin and 5-hydroxytryptamine in humans. Cephalalgia 1991;11:175-82.

115. Sicuteri F, Testi A, Anselmi B. Biochemical investigations in headache: Increase in the hydroxyindolacetic acid excretion during migraine attacks. Int Arch Allergy 1961;19:55-8.

116. Anthony $M$, Hinterberger $H$, Lance JW. Plasma serotonin in migraine and stress. Arch Neurol 1967;16:544-52.

117. Curran DA, Hinterberger H, Lance JW. Total plasma serotonin, 5-hydroxyindolacetic acid and $\mathrm{p}$-hydroxy-m-methoxymandelic acid excretion in normal and migrainous subjects. Brain 1965;88:997-1007

118. Kimball RW, Friedman AP, Vallejo E. Effect of serotonin in migraine patients. Neurology $1960 ; 10: 107-11$.

119. Feniuk W, Humphrey PPA, Perren MJ, Connor HE, Whalley ET. Rationale for the use of 5-HT - like antagonists in the treatment of migraine. J Neurol 1991;238:557-61.

120. Ferrari MD, Saxena PR. On serotonin and migraine: A clinical and pharmacological review. Cephalalgia 1993;13:151-65.

121. Moskowitz MA, Buzzi MG. Neuroeffector functions of sensory fibres: Implications for headache mechanisms and drug actions. J Neurol $1991 ; 238: S 18-22$.

122. Glover V, Peatfield R, Zammit Pace RM, et al. Platelet monoamine oxidase activity and headache. J Neurol Neurosurg Psychiat 1981:44:786-90.

123. Lance JW. 5-hydroxtryptamine and its role in migraine. Eur Neurol 1991;31:279-81.

124. Humphrey PPA. 5-Hydroxytryptamine and the pathophysiology of migraine. I Neurol 1991;238:\$38-44.

125. Berge $\mathrm{O}-\mathrm{G}$. Regulation of pain sensitivity, influence of prostaglandins. In: Sjaastad O, Bjerve KS, eds. Prostaglandins and Migraine. Cephalalgia 1986;6(Suppl 4):21-31.

126. Bono $G$, Micieli G, Sances $G$, Calvani $M$, Nappi G. L-SHTP treatment in primary headaches: an attempt at clinical identification of responsive patients. Cephalalgia 1984;4:159-65.

127. Hauge $T$. Catheter vertebral angiography. Acta Radiol 1954;Suppl 109:1-219. (Thesis)

128. Blau JN. The vascular theory of migraine - resuscitated or more moribunds. Headache 1989;29:384.

129. Lance JW, Lambert GA, Goadsby PJ, Duckworth JW. Brainstem 
influences on the cephalic circulation: experimental data from cat and monkey of relevance to the mechanism of migraine. Headache $1983 ; 23: 257-65$.

130. Lance JW. Solved and unsolved headache problems. Headache 1991:31:439-45.

131. Goadsby PJ, Piper RD, Lambert GA, Lance JW. The effect of activation of the nucleus raphe dorsalis on carotid blood flow. Am J Physiol 1985;248:R257-62.

132. Raskin NH, Hosobuchi Y, Lamb S. Headache may arise from perturbation of brain. Headache 1987;27:416-20.

133. Facchinetti F, Martignoni E, Gallai V, et al. Neuroendocrine evaluation of central opiate activity in primary headache disorders. Pain 1988;34:29-33.

134. Facchinetti F, Martignoni E, Fioroni L, Sames G, Genazzani AR. Opioid control of the hypothalamus-pituitary-adrenal axis cyclically falls in menstrual migraine. Cephalalgia 1990;10:51-6.

135. Lakin ML, Miller CH, Scott ML, Winters WD. Involvement of the pineal gland and melatonin in murine analgesia. Life Sci 1981;29:2543-51.

136. Genazzani AR, Trentini GP, Petraglia F, et al. Estrogens modulate the circadian rhythm of hypothalamic beta endorphin contents in female rats. Neuroendo 1990;52:221-4.

137. Gimeno MF, Ritta MN, Boriacossa A, Lazzarl M, Gimeno AL, Cardinali DP. Inhibition by melatonin of prostaglandin synthesis in hypothalamus, uterus and platelets. In: Birau N, Schlott W, eds. Melatonin: Current Status and Perspectives. Advances in the Biosciences. Oxford: Pergamon Press, 1980:147-50.

138. Murialdo $G$, Fonzi S, Costelli $P$, et al. Urinary melatonin excretion throughout the ovarian cycle in menstrually related migraine. Cephalalgia 1994;14:205-9.

139. Claustrat B, Loisy C, Brun J, Beorchia S, Arnaud JL, Chazot G. Nocturnal plasma melatonin levels in migraine: A preliminary report. Headache 1989;29:241 -4.

140. Kontos HA. Cerebral microcirculation in stroke. In: Barnett HJM, Mohr JP, Stein BM, Yatsu FM, eds. Stroke Pathophysiology, Diagnosis and Management. New York: Churchill Livingstone, 1986:91-6.

141. Sjaastad O. Cluster Headache Syndrome. Philadelphia: WB Saunders, 1992.

142. Kudrow L. Cluster headache. In Blau IN, ed. Migraine. London: Chapman and Hall, 1987:113-30.

143. Sjaastad $O$, Dale I. Evidence for a new (?) treatable headache entity. Headache 1974;14:105-8.

144. Antonaci F, Sjaastad O. Chronic paroxysmal hemicrania (CPH): A review of the clinical manifestations. Headache 1989;29:648-56.

145. Ekbom K, Nitroglycerin as a provocative agent in cluster headache. Arch Neurol 1968:19:487-93.

146. Ekbom K, Lindall J. Effect of induced rise of blood pressure on pain in cluster headache. Acta Neurol Scand 1970;46:585-600.

147. Ekbom K. Some observations on pain in cluster headache. Headache $1975 ; 14: 219-25$.

148. Kawamura J, Meyer JS, Terayama Y, Weathers S. Cerebral hyperemia during spontaneous cluster headaches with excessive cerebral vasoconstriction to hypoxia. Headache 1991;31:222-7.

149. Norris JW, Hachinski VC, Cooper PW. Cerebral blood flow changes in cluster headache. Acta Neurol Scand 1976;54:371-4

150. Henry PY, Vernhet J, Orgogozo JM, Caille JM. Cerebral blood flow in migraine and cluster headache. Res Clin Stud Headache $1978: 6: 81-8$.

151. Krabbe AAE, Henriksen $\mathrm{L}$, Olsen J. Tomographic determination of cerebral blood flow during attacks of cluster headache. Cephalalgia 1984:4:17-23.

152. Hørven I, Nornes $H$, Sjaastad O. Different comeal indentation pulse pattern in cluster headache and migraine. Neurology 1972:22:92-8.

153. Hørven I, Sjaastad $O$. Cluster headache syndrome and migraine. Ophthalmological support for a two entity theory. Acta Ophthalmol 1977;55:35-51.

154. Sjaastad O. Chronic paroxysmal hemicrania. In: Rose FC, ed. Handbook of Clinical Neurology, revised series 4. Amsterdam: Elsevier. 1986;48:257-66.

155. Sjaastad $O$. Chronic paroxysmal hemicrania: Clinical aspects and controversies. In: Blau JN, ed. Migraine. London: Chapman and Hall, 1987:113-30

156. Dahl A, Russell D, Nyberg-Hansen R, Rootwelt K. Cluster headache: transcranial doppler ultrasound and $\mathrm{rCBF}$ studies. Cephalalgia $1990 ; 10: 87-94$
157. Ekbom K, Greitz T. Carotid angiography in cluster headache. Acta Radiol 1970;10:177-80.

158. Hannerz J, Ericson K, Bergstrand G. Orbital phlebography in patients with cluster headache. Cephalalgia 1987;7:207-11.

159. Hardebo JE. On pain mechanisms in cluster headache. Headache 1990;31:91-106.

160. Hardebo JE. Activation of pain fibers to the internal carotid artery intracranially may cause the pain and local signs of reduced sympathetic and enhanced parasympathetic activity in cluster headache. Headache 1991;31:14-20.

161. Goadsby P, Edvinsson L. Human in vivo evidence for trigeminovascular activation in cluster headache. Neuropeptides changes and effects of acute attacks therapies. Brain 1994;117:427-34.

162. Kunkle EC, Anderson WB. Dual mechanisms of eye signs of headache in cluster pattem. Trans Am Neurol Assoc 1960;85:75-9.

163. Sjaastad O, Rinck P. Cluster headache: MRI studies of the cavernous sinus and the base of the brain. Headache 1990;30:350-1.

164. Gawel HJ, Krajewski A, Luo YM, Ichise M. The cluster diathesis. Headache 1990;30:652-5.

165. Raskin NH. Cluster headache localization. Headache 1989;29:579-80.

166. Fanciullacci M, Pietrini U, Gatto G, Boccum M, Sicuterl F. Latent dysautonomic pupillary latralization in cluster headache: A pupillometric study. Cephalalgia 1982;2:135-44.

167. Salvesen R, de Souza Carvalho D, Sjaastad O. Homer's syndrome: Sweat gland and pupillary responsiveness in two cases with probable 3rd neurone dysfunction. Cephalalgia 1989;9:63 70.

168. Salvesen R, de Souza Carvalho D, Sand T, Sjaastad O. Cluster headache: Forehead sweating pattern during heating and pilocarpine test. Cephalalgia 1988:8:245-53.

169. Sjaastad $O$. Cluster headache: On the inadequacy of existing hypotheses concerning the origin of the autonomic phenomena. Cephalalgia $188 ; 8: 133-7$.

170. Salvesen R, Bogucki A, Wysocka-Bakowska MM, Antonaci F, Fredriksen TA, Sjaastad $O$. Cluster headache pathogenesis: A pupillometric study. Cephalalgia 1987;7:273-84.

171. Anthony M, Lance JW. Whole blood histamine and plasma serotonin in cluster headache. Austr Assoc Neurol 1971;8:43-6.

172. Sjaastad $O$. Is histamine of significance in the pathogenesis of headache? In: Diamond S, Dalessio DJ, Graham JR, Medina JL, eds Vasoactive Substances Relevant to Migraine. Springfield: Charles C Thomas, 1975:45-66.

173. Sicuteri F, Fanciullacci M, Nicolodi M, et al. Substance P theory: A unique focus on the painful and painless phenomena of cluster headache. Headache 1990;30:69-79.

174. Bill A, Stjernschantz J, Mandahl A, Brodin E, Nilsson G. Substance P. Release on trigeminal nerve stimulation, effects in the eye. Acta Physiol Scand 1979;106:371-3.

175. Fitzgerald M. Capsaicin and sensory neurons: A review. Pain 1983;15:109-30.

176. Geppetti P, Fusco BM, Marabini S, Maggi CA, Fanciullacci M, Sicuteri $F$. Secretion, pain and sneezing induced by the application of capsaicin to the nasal mucosa in man. Br J Pharmacol 1988;93:509-14.

177. Sicuteri F, Fusco BM, Marabini S, Fanciullacci M. Capsaicin as a potential medication for cluster headache. Med Sci Res 1988;16:1079-80.

178. Marks DR, Rapoport A, Padla D, et al, A double-blind placebo-controlled trial of intranasal capsaicin for cluster headache. Cephalalgia 1993;13:114-6.

179. Horton BT. Histaminic cephalgia (Horton's headache or syndrome) MD State Med J 1961;10:178-203.

180. Dexter JD, Weltzman ED. The relationship of nocturnal headache to sleep stage patterns. Neurology 1970;20:513-8.

181. Anonymous. Diagnostic classification of sleep and arousal disorders. Sleep 1979;2:1.

182. Graham JR. Cluster headache: The relation to arousal relaxation and autonomic tone. Headache 1990;30:145 -51.

183. Graham JR. Some clinical and theoretical aspects of cluster headache. In: Saxena PR, ed. Migraine and Related Headaches. Rotterdam: Erasmus University, 1975:27-40.

184. Joseph R, Rose FC. Cluster headache and herpex simplex: An association? BMJ $1985 ; 290: 1625-6$.

185. De Angelis LM, Payne R. Lymphomatous meningitis presenting as atypical cluster headache. Pain 1987;30:211-6.

186. Ramadan NM. Postmeningitic cluster headache. Neurology 1994:44:2208. 
187. Kudrow L. McGinty DJ, Phillip ER, Stevenson M. Sleep apnea in cluster headache. Cephalalgia 1984;4:33-8.

188. Kudrow L. A possible role of the carotid body in the pathogenesis of cluster headache. Cephalalgia 1983:3:241-7.

189. Zhao JM, Schaanning J, Sjaastad O. Cluster headache: The effect of low oxygen saturation. Headache 1990;30:656-9.

190. Antonaci F, Zhao JM, Schaanning J, Sand T, Sjaastad O. The effect of hyperventilation in cluster headache patients. Headache 1991;31:146-50.

191. Portency RK, Abissi CJ, Lipton RB, et al. Headache in cerebrovascular disease. Stroke 1984;15:1009-12.

192. Goerelick PB, Hier DB, Caplan CR, Laugenberg P. Headache in acute cerebrovascular disease. Neurology 1986:36:1445-50.

193. Edmeads $J$. The headaches of ischemic cerebrovascular disease. Headache 1979;19:345-9.

194. Mohr JP. Caplan CR, Melski JW, et al. The Harvard Cooperative Stroke Registry: A prospective registry. Neurology 1978;28:754-62.

195. Mitsias P, Ramadan NM. Headache in ischemic cerebrovascular disease. Part I: Clinical features. Cephalalgia 1992;12:269-74.

196. Mitsias P. Ramadan NM. Headache in ischemic cerebrovascular disease. Part II: Mechanisms and predictive value. Cephalalgia 1992;12:341-4.

197. Vestergaard K, Anderson G, Nelson MI, Jensen TS. Headache in stroke. Stroke 1993;24:1621-4.

198. Arboix A. Massons J, Oliveres M. Arribas MP, Titus F. Headache in acute cerebrovascular disease a prospective clinical study in 240 patients. Cephalalgia 1994:14:37-40.

199. Koudstaad PJ, van Gijn J, Kapelle LJ. Headache in transient or permanent cerebral ischemia. Stroke 1991:22:754-9.

200. Ray BS, Wolff HG. Experimental studies on headache. Pain sensitive structures of the head and their significance in headache. Arch Surg 1940;41:813-56.

201. Fisher $\mathrm{CM}$. The headache and pain of spontaneous carotid dissection. Headache 1982;22:60-5.

202. Hart RG, Easton JD. Dissection of cervical and cerebral arteries. Neurologic Clinics 1983;1:155-82.

203. Mas JL, Goeau C, Bousser MG, Chiras JCh, Vesset JM, Touboud PJ. Spontaneous dissecting aneurysins of the intemal carotid and vertebral arteries - two case reports. Stroke 1985;16:125-9.

204. Caplan LR, Zarius CK. Hemmati M. Spontaneous dissection of the extracranial vertebral arteries. Stroke 1985:16:1030-8.

205. Bogousslavsky J. Despland PA, Regli F. Spontaneous carotid dissection with acute stroke Arch Neurol 1987:44:137-40.

206. D'Anglejan-Chatillon J, Ribeiro V, Mas JL, Youl BD, Bousser MG. Migraine - a risk factor for dissection of cervical arteries. Headache 1989;29:560-1.

207. Biousse V, D'Anglejan-Chatillon J, Massiou H, Bousser MG. Head pain in non-tratumatic carotid artery dissection: A series of 65 patients. Cephalalgia 1994;14:33-6.

208. Feit $\mathrm{H}$. Further observations on the diagnosis and management of carotidynia. Headache 1982;22:86-8.

209. Raskin NH, Prusiner S. Carotidynia. Neurology 1977;27:43-6.
210. Roseman DM Carotidynia. A distinct syndrome. Acta Otolaryngol 1967:85:81-4.

211. Murray TJ. Carotidynia: a cause of neck and face pain Can Med Assoc J 1979;120:441-3.

212. Ostergaard $\mathrm{J}$. Headache as a warning symptom of impending aneurysmal subarachnoid haemorrhage. Cephalalgia 1991;11:53-5.

213. Parkinson D, Bachers G. Arteriovenous malformations. Summary of 100 consecutive supratentorial cases. J Neurosurg 1987:66:35-9.

214. Leblanc $\mathrm{R}$. The minor leak preceding subarachnoid hemorrhage. J Neurosurg 1987;66:35-9.

215. Day JW, Raskin NH. Thunderclap headache: Symptom of unruptured intracranial aneurysms. Lancet 1986;ii: 1247-8.

216. Wijdicks EFM, Kerkhoff H, Van Gijn J. Long-term follow-up of 71 patients with thunderclap headache mimicking subarachnoid hemorrhage. Lancet 1988;ii:68-70.

217. Raps EC, Rogers J, Galetta SL, et al. The clinical spectrum of unruptured intracranial aneurysms. Arch Neurol 1993;50:265-8.

218. Hughs T. Pathological changes associated with cerebral vasospasm. In: Bouillin DJ, ed. Cerebral Vasospasm. Chichester: John Wiley and Sons, 1980:171-206

219. Juul R, Aakhus S, Bjørnstad K, Gisvold SE, Brubakk AO, Edvinsson L. Calcitonin gene-related peptide (human $\alpha$-CGRP) counteracts vasoconstriction in human subarachnoid haemorrhage. Neurosci Lett 1994; 170:67-70.

220. Mackenzie I. The clinical presentation of cerebral angioma. A review of fifty cases. Brain 1953:76:184-214.

221. Pereira Monteiro JM, Rosas MJ, Correia AP, Vaz AR. Migraine and intracranial vascular malformations. Headache 1993;33:563-5.

222. Haas DC. Arteriovenous malformations and migraine. Case reports and an analysis of the relationship. Headache 1991;31:509-13.

223. Bruyn GW. Intracranial arteriovenous malformation and migraine. Cephalalgia 1984:4:191-207.

224. Waters WE. Headache and blood pressure in the community. BMJ 1971;i:142-3.

225. Weiss NS. Relation of high blood pressure to headache, epistaxis and selected other symptoms. N Engl J Med 1972;28:631-3.

226. Kottke TE, Tuomilehto J, Puska P, Salonen JT. The relationship of symptoms and blood pressure in a population sample. Int J Epidemiol 1979:8:355-9.

227. Chatellier G, Degoult P, Devries C, Vu HA, Plouln PF, Menard J. Symptom prevalence in hypertensive patients. Eur Heart $J$ 1982;3(Suppl C):45-52.

228. Dinsdale HB. Hypertensive encephalopathy. In: Barnett HJM. Mohr JP, Stein BM, Yatsu FM. eds. Stroke. Pathophysiology, Diagnosis and Management. New York: Churchill Livingstone, 1986:869-74.

229. Healton EB, Brust JC, Feinfeld DA, Thompson GE. Hypertensive encephalopathy and the neurologic manifestations of malignant hypertension. Neurology 1982;32:127 32.

230. Thomas JE, Rooke ED, Kvale WF. The neurologist's experience with pheochromacytoma: A review of 100 cases. JAMA 1966:197:754-8.

231. Lance JW, Hinterberger H. Symptons of pheochromacytoma with particular reference to headache, correlated with catecholamine production. Arch Neurol 1976;33:281-8. 


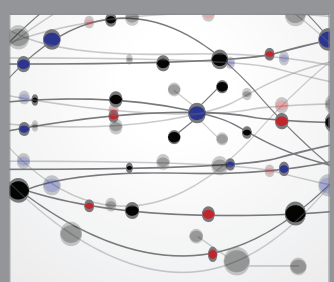

The Scientific World Journal
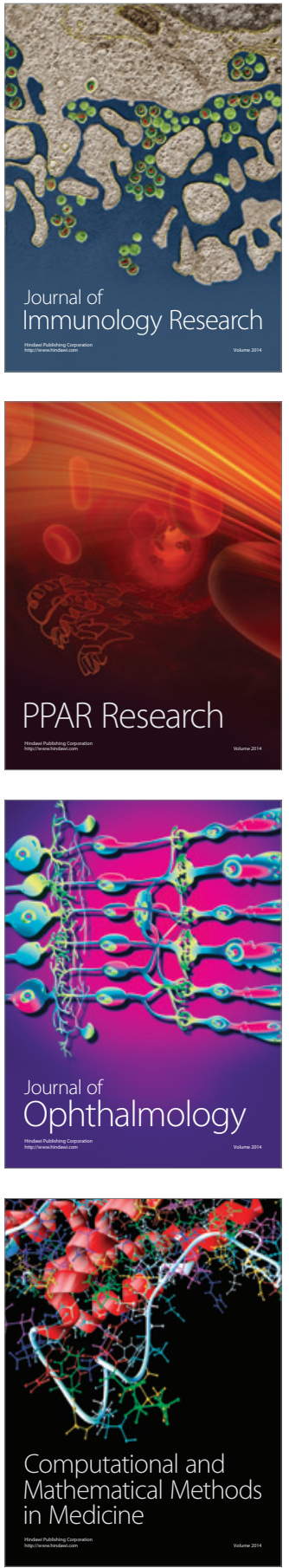

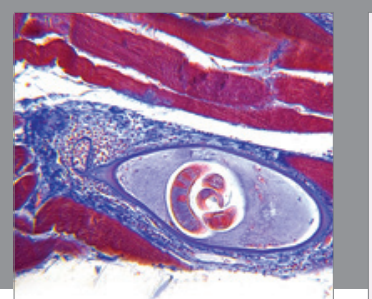

Gastroenterology Research and Practice

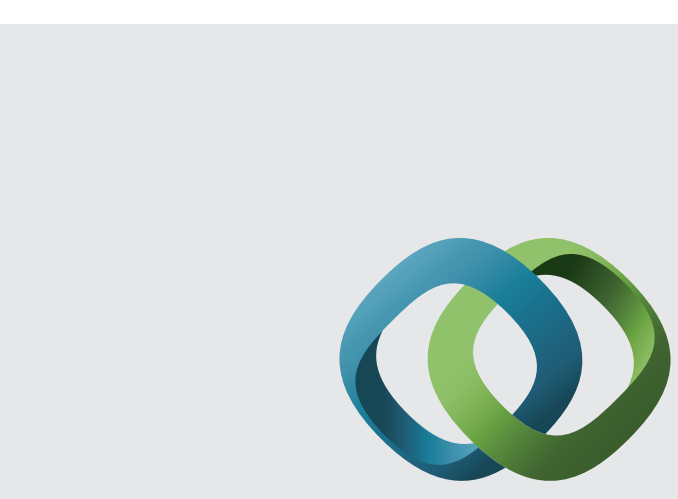

\section{Hindawi}

Submit your manuscripts at

http://www.hindawi.com
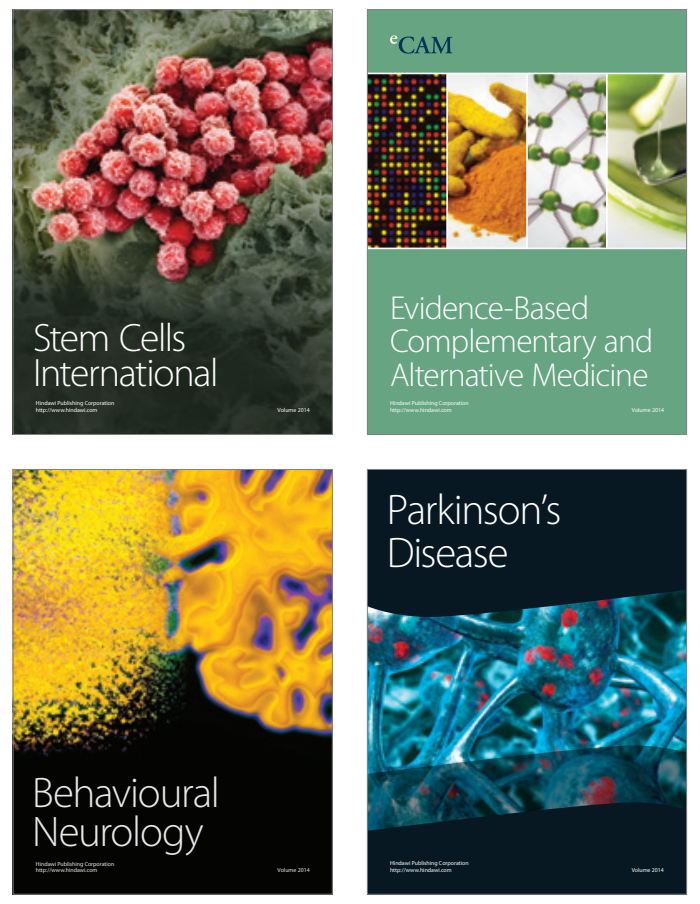
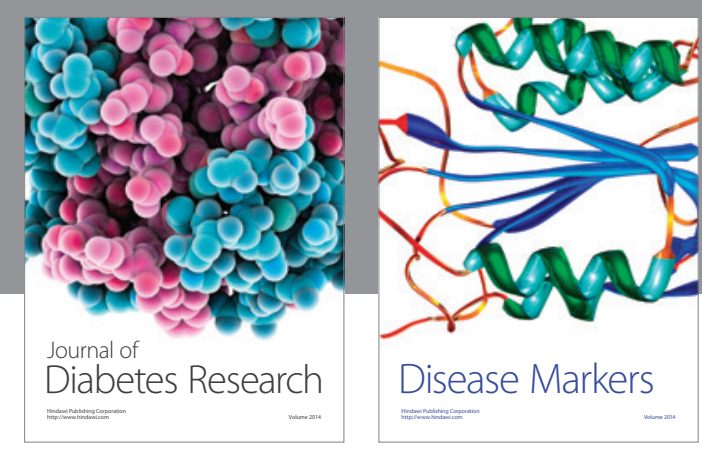

Disease Markers
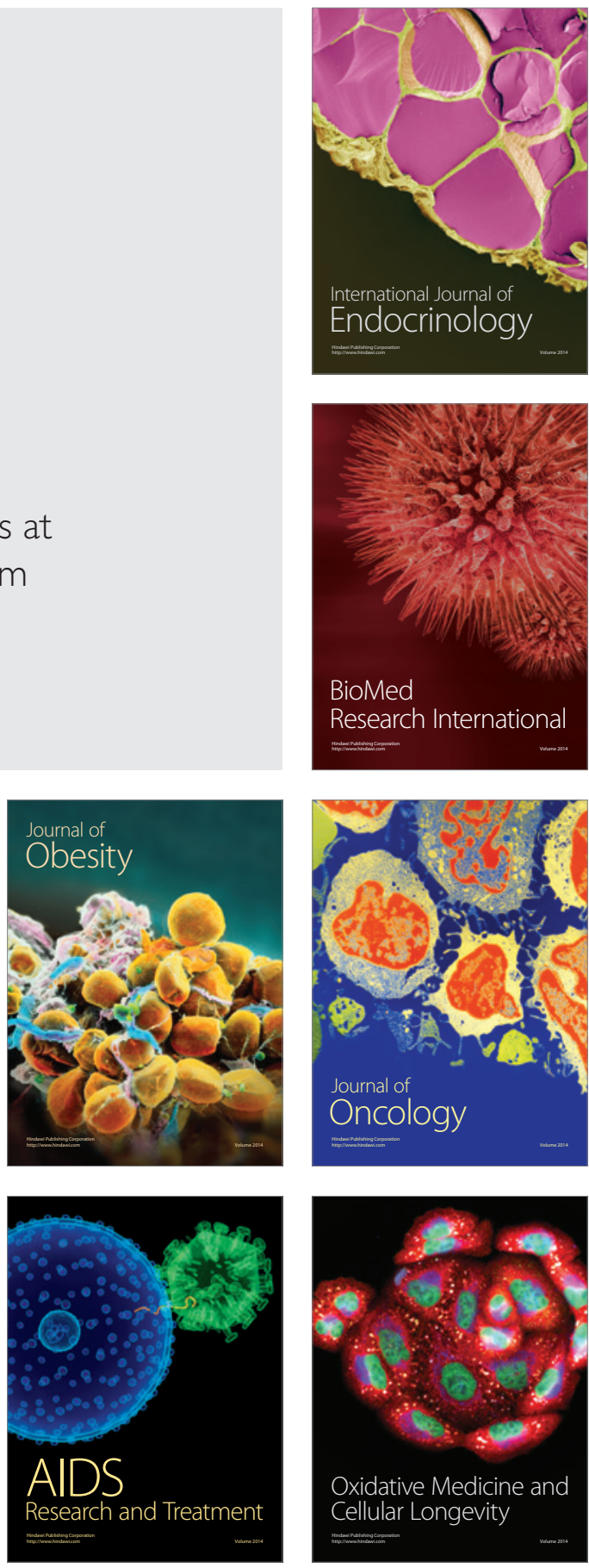